\title{
A Systematic Review of Influenza Epidemiology and Surveillance in the Eastern Mediterranean and North African Region
}

\author{
Samira Soudani · Alireza Mafi · Zayid Al Mayahi · Sultan Al Balushi • \\ Ghassan Dbaibo · Salah Al Awaidy · Amine Amiche
}

Received: June 11, 2021 / Accepted: August 27, 2021 / Published online: January 8, 2022

(C) The Author(s) 2022

\section{ABSTRACT}

Seasonal influenza represents a huge health burden, resulting in significant mortality and morbidity. Following the 2009 H1N1 pandemic, focus has been directed on the burden of influenza globally. Country and regional disease burden estimates play important roles in helping inform decisions on national influenza intervention programmes. Despite improvements in influenza surveillance following the 2009 pandemic, many opportunities remain unexplored in the Eastern Mediterranean and North African (EMNA) region, which has a high prevalence of patients with chronic disease and

Supplementary Information The online version contains supplementary material available at https:// doi.org/10.1007/s40121-021-00534-3.

S. Soudani · A. Amiche ( $\square)$

Sanofi Pasteur, OneJLT 3rd floor, Dubai, UAE

e-mail: amine.amiche@sanofi.com

A. Mafi

Sanofi Pasteur, Istanbul, Turkey

Z. Al Mayahi · S. Al Balushi

Ministry of Health, Muscat, Oman

G. Dbaibo

Center for Infectious Diseases Research, American

University of Beirut, Beirut, Lebanon

S. Al Awaidy

Office of Health Affairs, Ministry of Health, Muscat, Oman thus a population at high risk of influenza complications. We conducted a systematic literature review of Embase, Medline, Scopus and the Cochrane Database of Systematic Reviews from 1 January 1998 to 31 January 2020 covering the EMNA region with the aim to describe the epidemiology of influenza in the region and assess the influenza epidemiological surveillance research landscape. Relevant data on study characteristics, population, clinical/virology characteristics and epidemiology were extracted and summarised descriptively. Of the 112 studies identified for inclusion, 90 were conducted in the Eastern Mediterranean region, 19 in North Africa and three across the EMNA region. Data were reported on 314,058 laboratory-confirmed influenza cases, 96 of which were derived from surveillance systems. Amongst the surveillance studies, the percentage of positive cases reported ranged from $1 \%$ to $100 \%$. The predominantly identified influenza strain was strain A; H1N1 was the most prominent circulating subtype. Typing was performed in approximately $75 \%$ and subtyping in $50 \%$ of studies, respectively. Data on those considered most at risk for influenza complications were collected in $21 \%$ of studies, highlighting a regional gap for these data. Our review reveals existing gaps in regional estimates of influenza health and economic burden, hospitalisation rates and duration, and highlights the need for robust and high-quality epidemiology data to help inform public health interventions. 
Keywords: Influenza; Middle East; North Africa; Epidemiology; Influenza surveillance

\section{Key Summary Points}

Why carry out this study?

The Eastern Mediterranean and North African (EMNA) region is geographically contiguous, making it an important region for influenza surveillance, yet the burden of disease is not well characterized in the region, and there are several countries with little to no data on influenza epidemiology

The region has a high prevalence of patients with chronic disease and thus a population at high risk of seasonal influenza complications; hence, these data are essential in helping to inform decisions on national and regional influenza intervention programmes

This study aimed to describe the epidemiology of influenza in the EMNA region and to assess the landscape for influenza surveillance and epidemiological research

\section{What was learned from the study?}

The study highlighted important gaps in regional estimates of influenza health and economic burden, hospitalisation rates and duration of hospital stay and a lack of surveillance standardization for influenza across countries

There is a high need for robust and highquality epidemiology data and strengthening of surveillance systems to help inform public health interventions in the EMNA region

\section{INTRODUCTION}

Influenza represents a huge global health burden, with an estimated 1 billion cases occurring annually [1]. The World Health Organization (WHO) estimates that globally there are 3-5 million cases of severe illness, and 290,000-650,000 deaths annually due to influenza-related respiratory diseases alone $[2,3]$. This estimate does not include influenzarelated deaths in patients with chronic diseases such as cardiovascular disease or cardiovascular events and their complications.

Much of our understanding of seasonal influenza is derived from epidemiological data collected from western Europe and North America, whereas epidemiological data from the Eastern Mediterranean and North African (EMNA) region are less well characterised. The list of countries in this region can vary depending on the institution defining them. For the purposes of this review, the following countries were considered part of the EMNA region: Afghanistan, Algeria, Bahrain, Djibouti, Egypt, Iraq, Iran, Israel, Jordan, Kuwait, Lebanon, Libya, Morocco, Oman, Pakistan, Qatar, Saudi Arabia, Somalia, Sudan, Syria, Tunisia, Turkey, United Arab Emirates and Yemen. It has recently been shown that the seasonality of influenza epidemics for most countries in the EMNA region is in line with that reported for western Europe and North America [4]. With the exception of a few countries in the Arab peninsula, the influenza season primarily peaks in the winter between January and March in this region. Secondary peaks, with smaller amplitude, in general tend to occur in either spring or summer (May to July) or autumn (September to November) [4]. The notable exceptions are Bahrain and Qatar, where the primary peak is seen to occur earlier (November to December) and a secondary peak (of sizeable amplitude) occurs in March; Jordan, which has a secondary peak (only slightly smaller than the primary peak) in April; and Oman, where the primary and secondary peaks are of similar amplitude and take place in January and March, respectively [4]. 
Risk factors or risk groups for severe disease following seasonal influenza infection are well documented and include those with chronic medical conditions such as cardiovascular disease (or cardiovascular events), chronic pulmonary disease, metabolic disorders and immunodeficiency and young children, pregnant women, elderly or frail individuals and healthcare workers [5]. The EMNA region has a high prevalence of patients with chronic diseases and thus a population at high risk of seasonal influenza complications [2, 6, 7]. Influenza infections and their severe complications result in significant economic and societal burden, particularly among those in risk groups or with risk factors and/or whom are prone to severe complications $[2,3,8]$.

In humans, the vast majority of influenza disease is caused by the influenza type $\mathrm{A}$ and $\mathrm{B}$ viruses, and infection is preventable by vaccination [9]. The relative proportion of influenza cases caused by each strain is subject to annual variation as a result of antigenic drift, and at any one time there will be a mix of strains circulating among the general population [9]. The A strain is further subdivided into a number of subtypes, the current most commonly circulating being H3N2 and H1N1 (also known as H1N1pdm09). The B strain is classified by lineage, the currently circulating lineages being Yamagata (B/Y) and Victoria (B/V) [2]. The emergence of the H1N1 pandemic in 2009 highlighted the importance of influenza surveillance to enable countries to better understand influenza epidemiology and help them implement appropriate preventive strategies. The pandemic also highlighted weaknesses of health systems in preparedness and response to the next pandemic.

Epidemiological and virological surveillance have been improved in the region since the formation of the Eastern Mediterranean Acute Respiratory Infection Surveillance (EMARIS) network, but is still far from well established, particularly as the network only collects data on severe respiratory infections, but not non-severe cases $[10,11]$. In addition to improvement in virological laboratory assessments, the availability of data in the region has also increased as a result of the web-based influenza repository
FluNet, which was first launched in 1997 and provides a global tool for influenza virological surveillance [12]. The number of publications in this region relating to influenza epidemiology has grown since the 2009 pandemic, including a number of recent reports describing the epidemiology of influenza and disease burden in individual countries [13-15]. However, there is still a paucity of good-quality and consistent data looking at the region as a whole. Using a systematic literature review approach, we aimed to describe the epidemiology of influenza in the EMNA region and to assess the landscape for influenza surveillance epidemiological research.

\section{METHODS}

\section{Literature Search}

We conducted a comprehensive, systematic literature review of Embase, Medline, Scopus and the Cochrane Database of Systematic Reviews from 1 January 1998 to 31 January 2018 covering the EMNA region for the following countries: Afghanistan, Algeria, Bahrain, Djibouti, Egypt, Iraq, Iran, Israel, Jordan, Kuwait, Lebanon, Libya, Morocco, Oman, Pakistan, Qatar, Saudi Arabia, Somalia, Sudan, Syria, Tunisia, Turkey, United Arab Emirates and Yemen. As 'Arab world' and 'Middle East' are often used as acronyms for some of the countries in this region, we included these strings along with 'North Africa', 'Eastern Mediterranean Regional Office of WHO' (EMRO) and 'Eastern Mediterranean' amongst others in our search. A full list of search strings is given in Supplementary Table S1A. An updated search was conducted from 1 January 2018 through to 31 January 2020 for the same countries (Supplementary Table S1B). We did not evaluate the literature beyond this date in order to avoid potential implications on epidemiology as a consequence of the COVID-19 pandemic.

We also screened for laboratory-confirmed seasonal influenza infections, influenza-like illnesses (ILI) and severe acute respiratory infections (SARI) to identify any potential missed articles. Titles, abstracts, and full-text screening and selection were sequentially performed. This 
article is based on previously conducted studies and does not contain any new studies with human participants or animals performed by any of the authors.

\section{Selection Criteria}

Articles included were:

- Population-based studies with data of confirmed or suspected human influenza infections (including ILI and SARI)

- Studies of all age groups or for a specific age group or condition

- Studies reporting influenza incidence or mortality carried out for at least 1 year

- Studies reporting vaccine coverage for at least 1 year

We excluded any articles:

- Reporting on influenza infection as a secondary co-infection in the study population

- Studies reporting data of avian influenza viruses

- Epidemiological data and mortality estimated through mathematical modelling

- Animal-only studies

No relevant studies were identified through the assessment of grey literature. In addition, we performed a manual search of the bibliography included in other systematic reviews and meta-analyses of influenza epidemiology and surveillance in the EMNA region.

\section{Data Extraction}

Relevant data on study characteristics, study population, clinical/virology characteristics and epidemiology from the included articles were summarised using a standardised data-extraction form (see Supplementary Table S2 for full list of variables extracted). Where age was not specified for the population, or if data were reported from adult and paediatric populations combined, the age group was defined as the general population. Data were extracted by two independent reviewers into an Excel file (Microsoft Office). Discrepancies were resolved by consensus through a common review by the two reviewers. All data are summarised descriptively. If not reported in the article, frequencies (such as influenza positivity rates and percentage breakdown of influenza A and B and their subtypes) were back calculated using the reported numbers of cases, the appropriate population size as denominators.

\section{RESULTS}

A total of 9408 studies were initially identified and, following article screening, 112 studies were retained. A diagram of the article selection process is shown in Fig. 1.

Of the countries in the EMNA region across which we conducted our search, data were available for 18 countries (Afghanistan, Algeria, Bahrain, Egypt, Iran, Jordan, Lebanon, Libya, Morocco, Oman, Pakistan, Palestine, Qatar, Saudi Arabia, Tunisia, Turkey, United Arab Emirates and Yemen). The country of study setting and the number of studies retrieved are shown in Fig. 2. Ninety studies were conducted in the Eastern Mediterranean region and 19 in North Africa. Turkey, Iran and Saudi Arabia retrieved the highest number of articles $(25,24$ and 15 , respectively). The majority of studies $(n=89)$ were conducted during and/or after the 2009 pandemic.

Three studies were conducted across the EMNA region (Table 1) $[4,16,17]$. All three studies employed a surveillance study design and assessed the general population. The proportion of the 'at-risk' population was not reported in any of these studies. All three studies evaluated both influenza strains A and B; no other viruses were reported. Subtyping of the A strain was only performed in one of the studies, and only for the H1N1 and H3N2 strains which were reported to occur in $50.8 \%$ and $15.9 \%$ of the influenza positive cases; the remaining positive cases were identified as strain B (17.2\%) or not subtyped (16.1\%) [16].

The characteristics of all 112 studies conducted in the EMNA region are presented in Table 2. Eighty-four studies (75\%) reported a study population size of at least 200 patients. The majority of studies did not look at any specific age group but evaluated across a range 


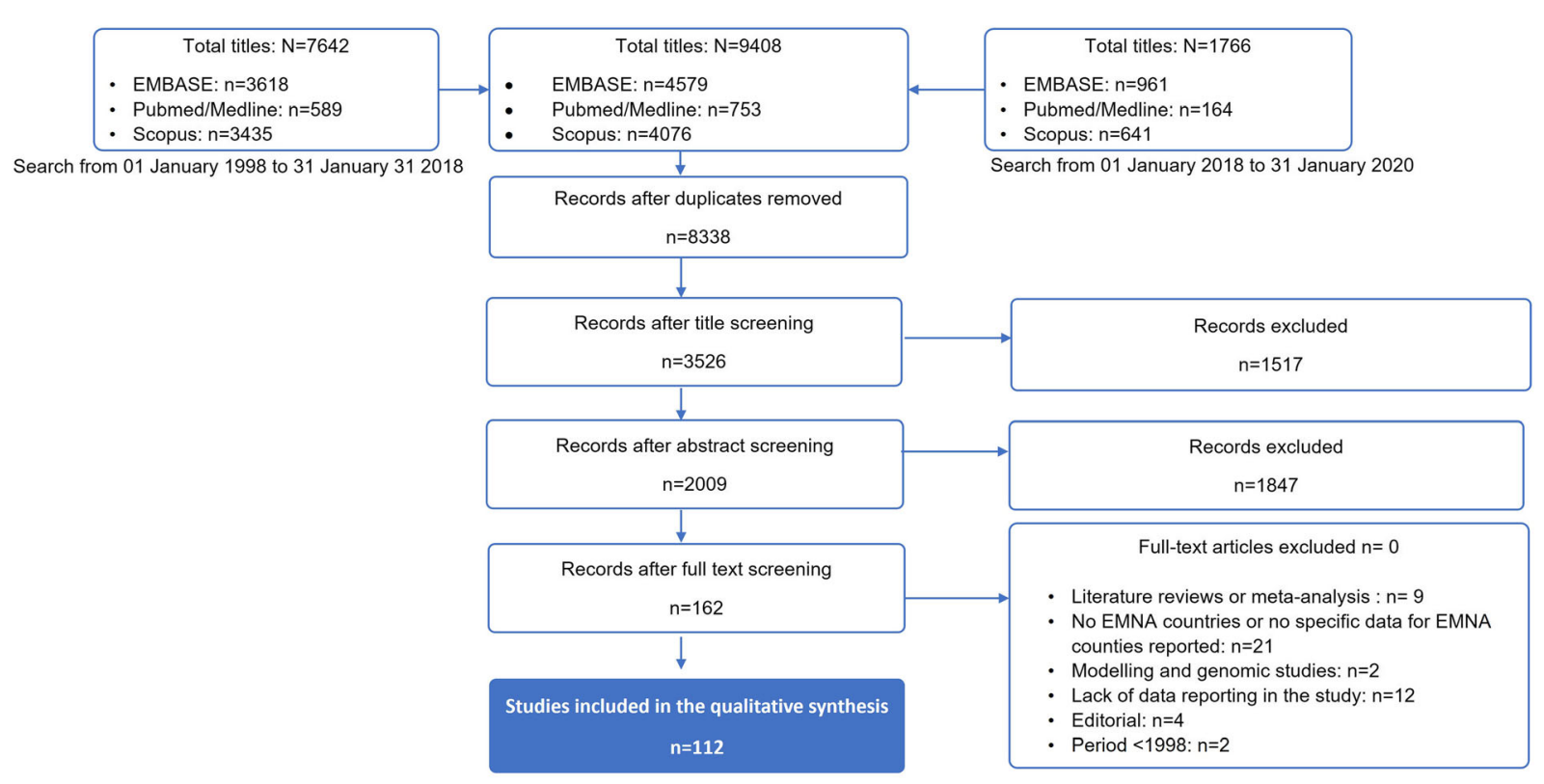

Search from January 01, 1998 to January 31, 2020

Fig. 1 Article selection procedure and number of studies included

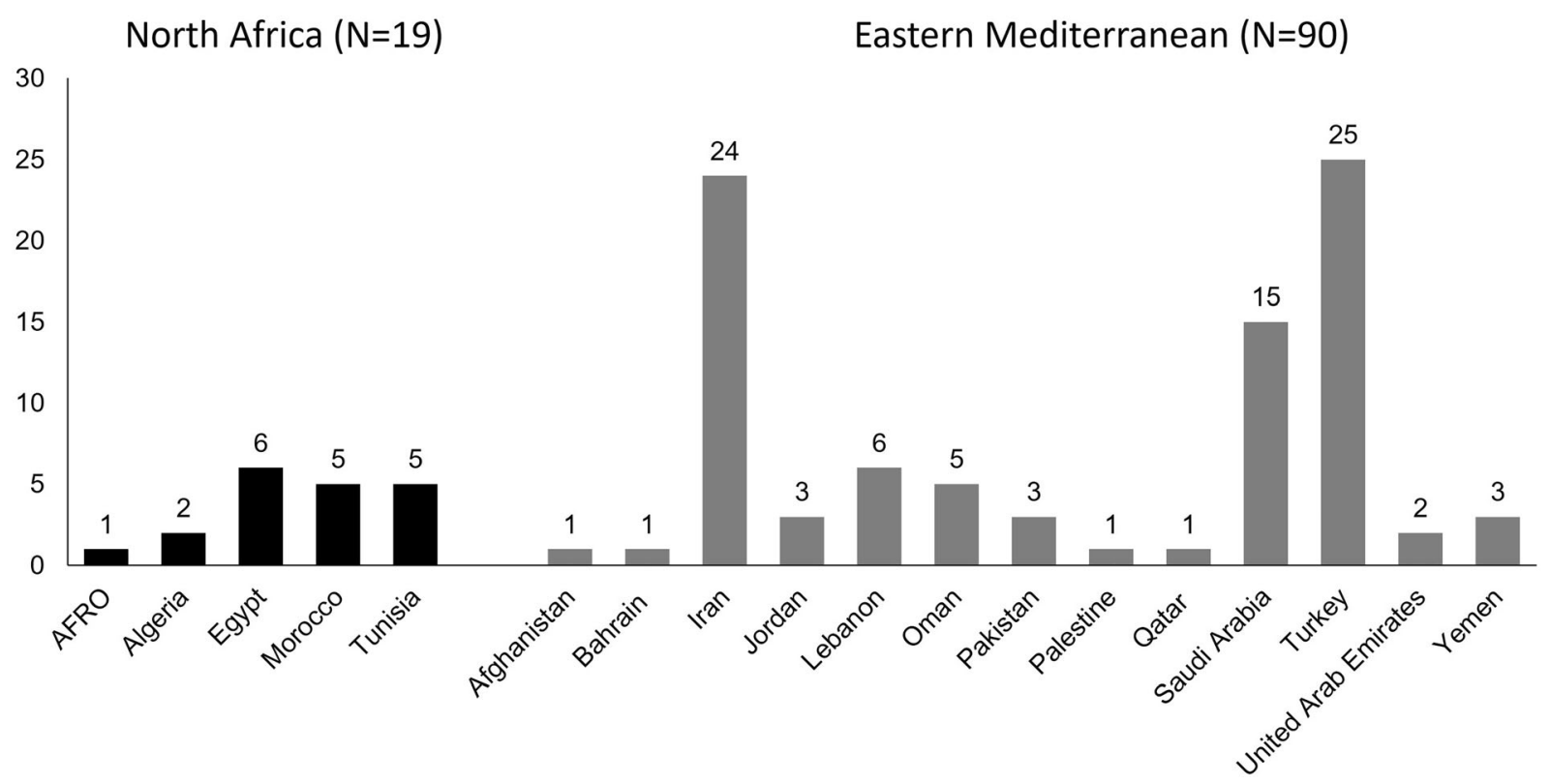

Fig. 2 Country of study setting and the number of studies retrieved

of ages or the general population (i.e. both paediatric and adult populations combined, across a range of ages or where all age groups were included, $[n=69,62 \%])$. Eighteen studies $(16.1 \%)$ were conducted in a dults only and 20 studies (17.9\%) in patients aged less than
18 years old. Age was not reported in five (4\%) of the studies. The average proportion of female individuals included in the studies was $46 \%$. The percentage of patients with chronic medical conditions or risk factors predisposing them to an increased risk of complications from 


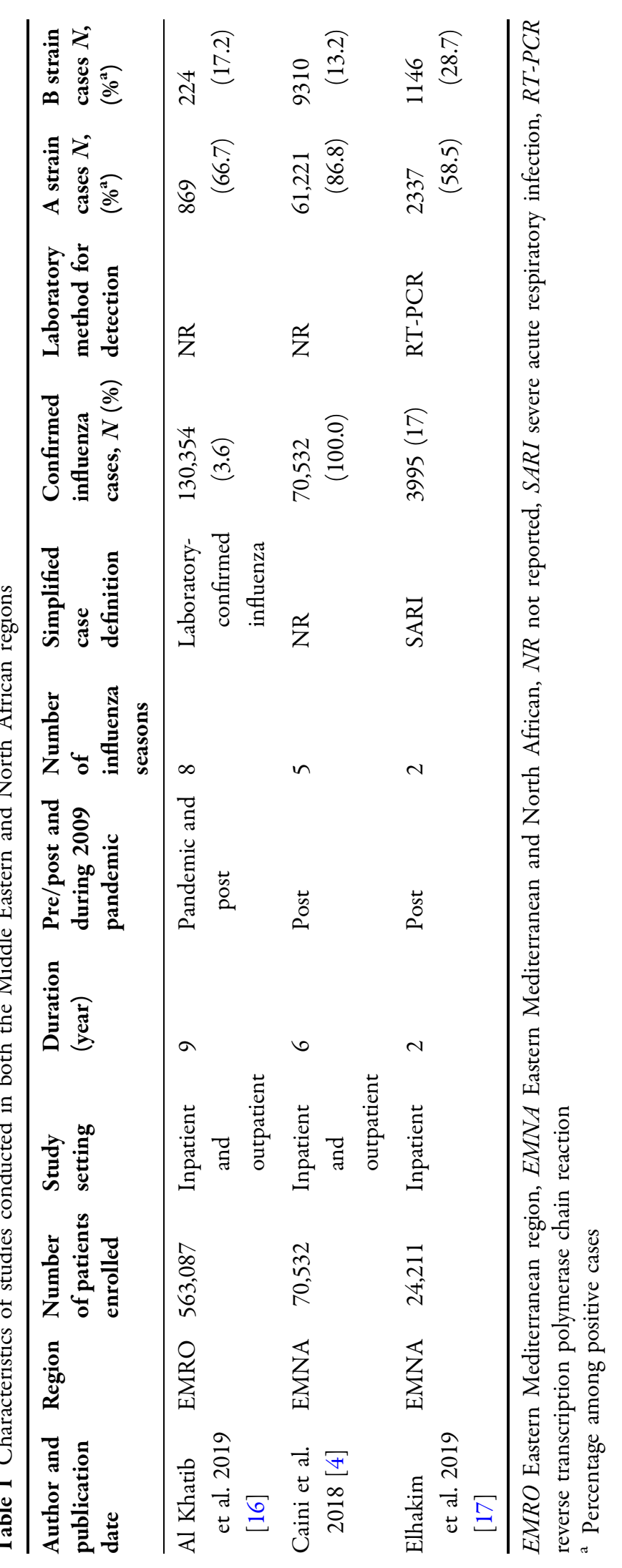




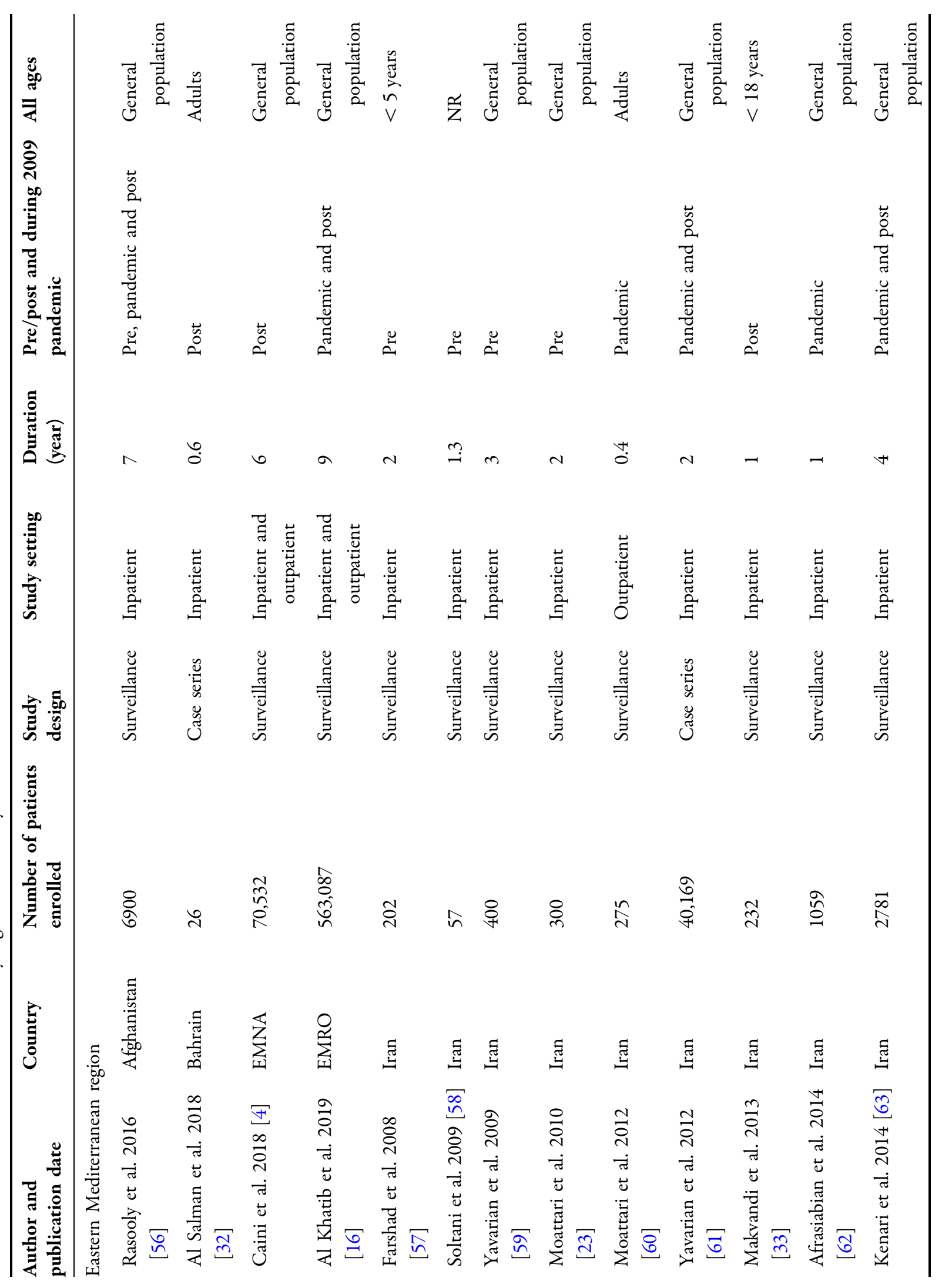




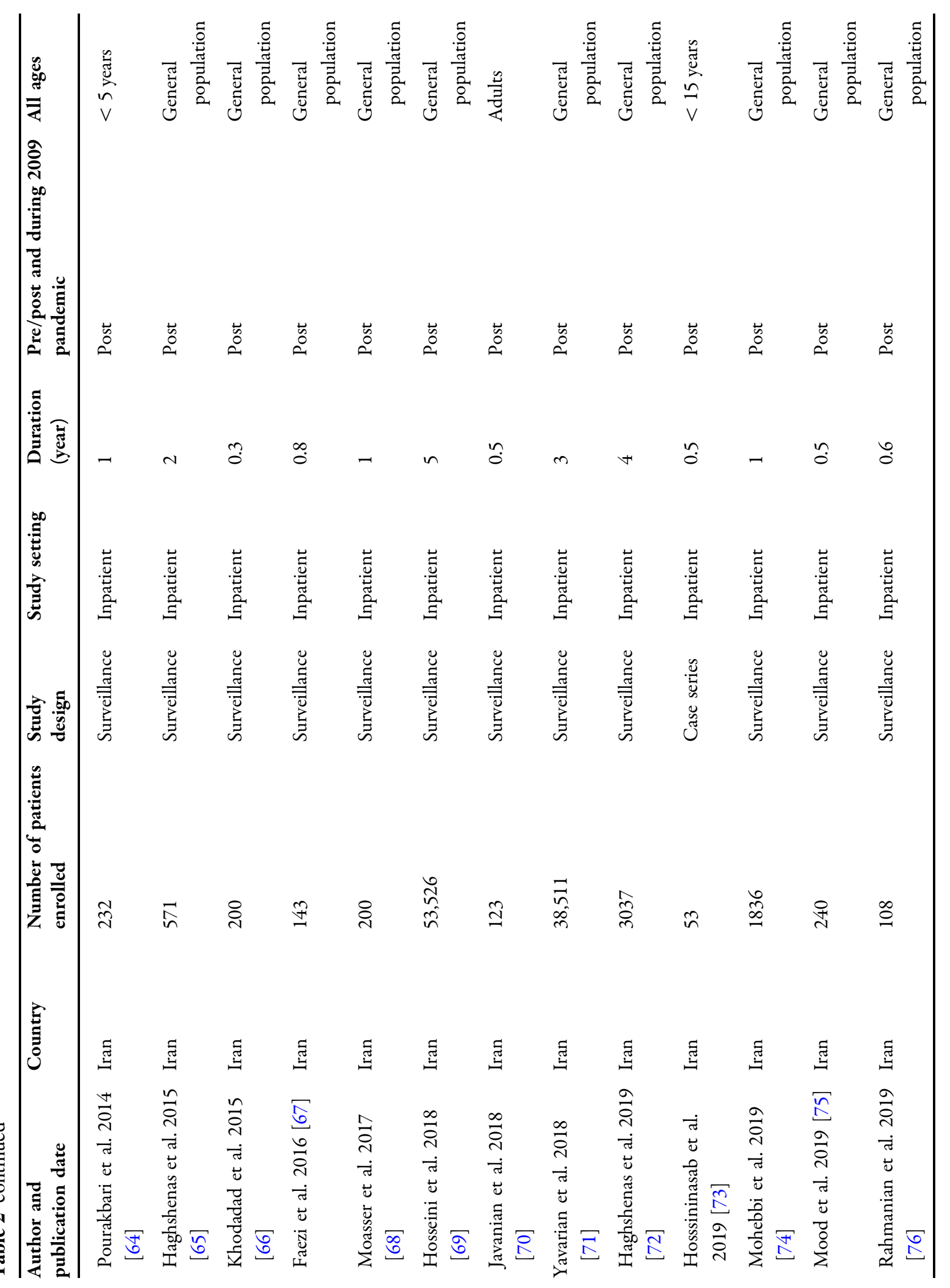




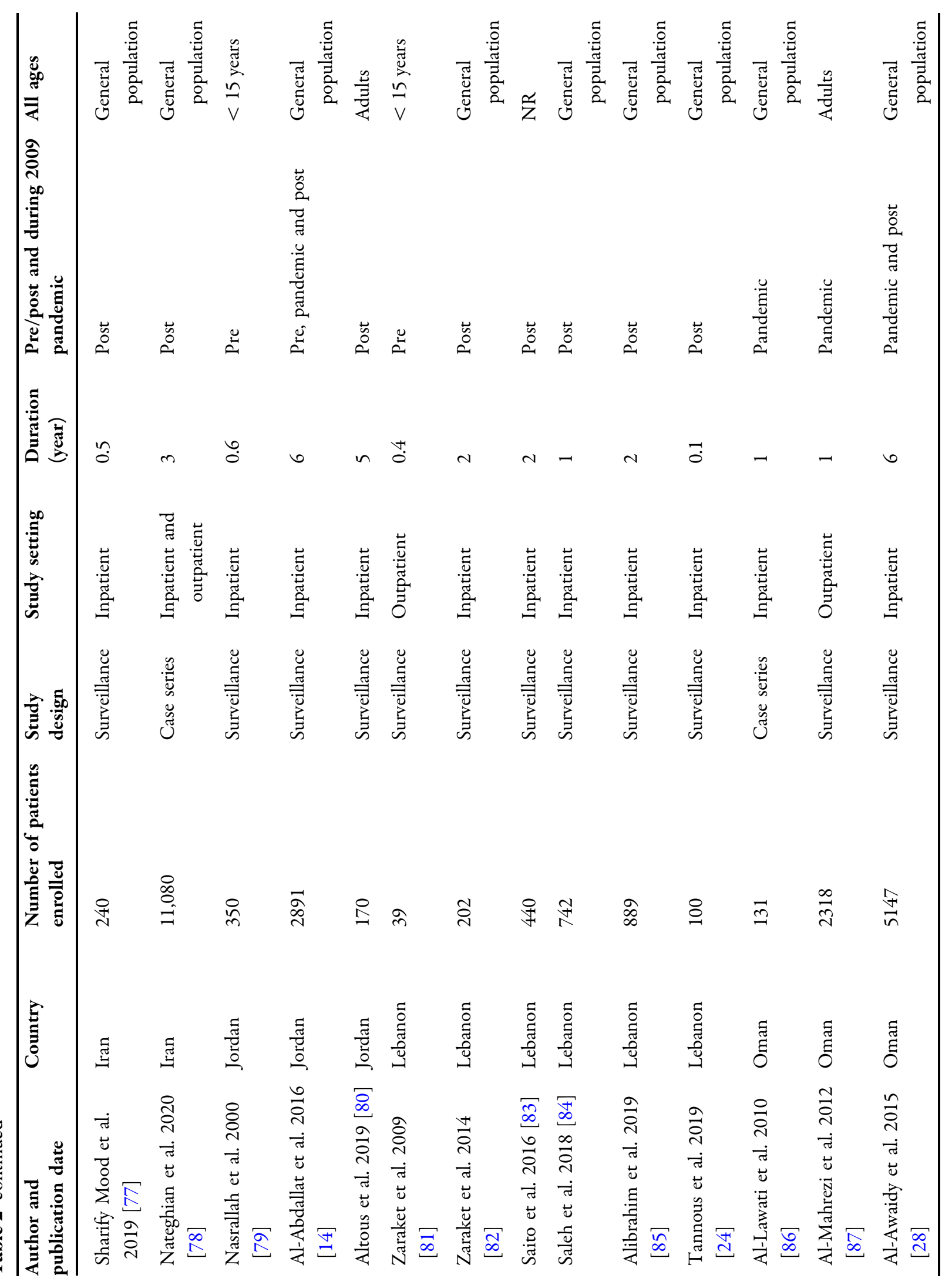




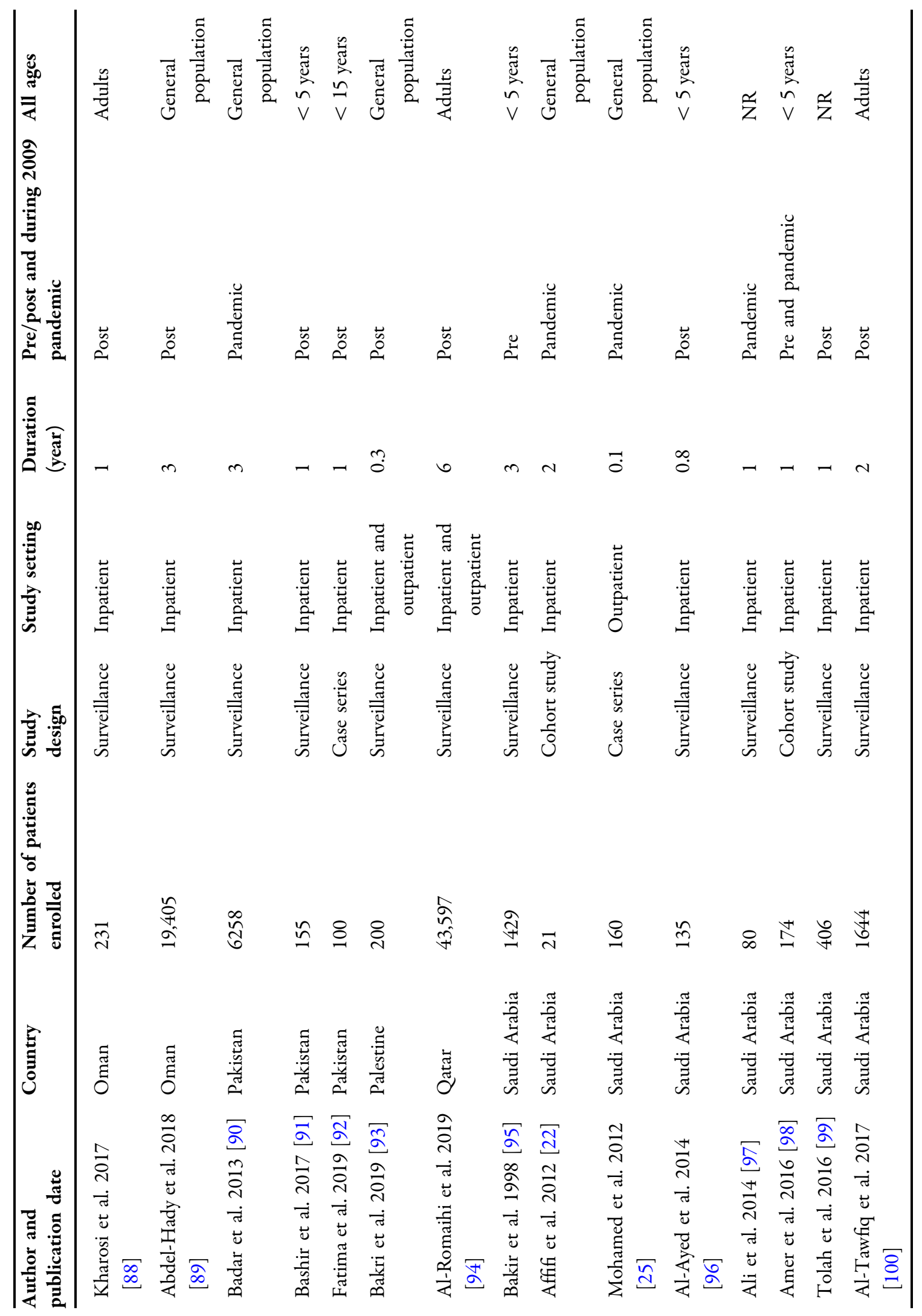




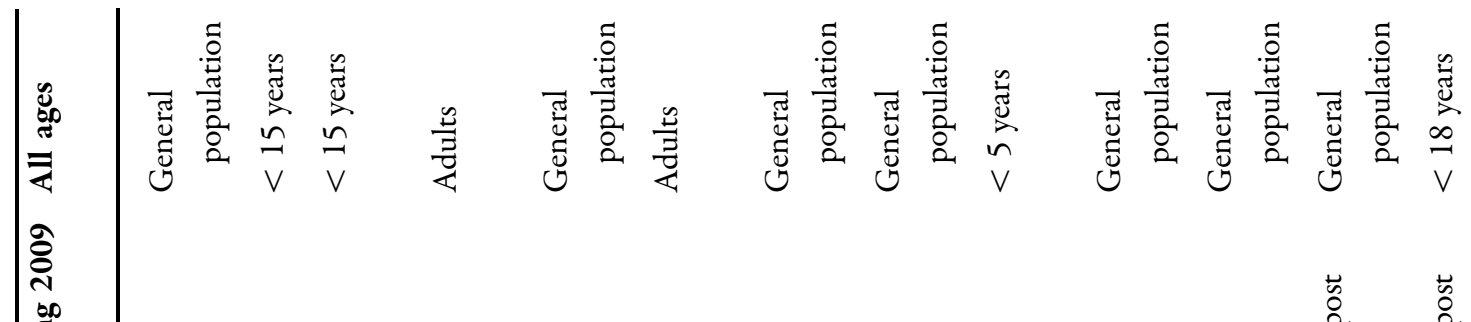

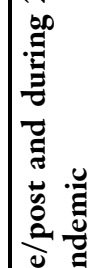

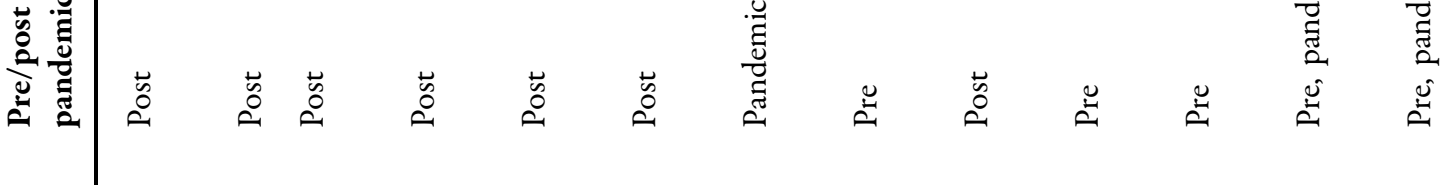

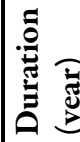

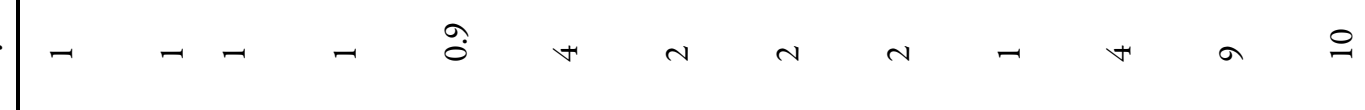

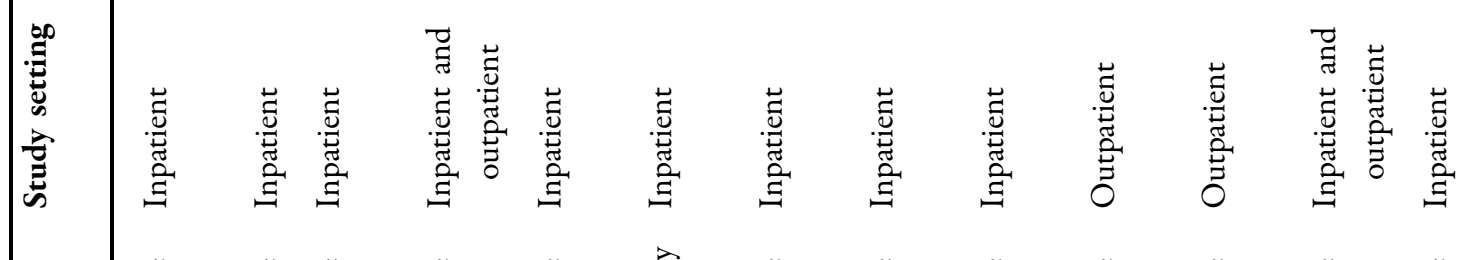

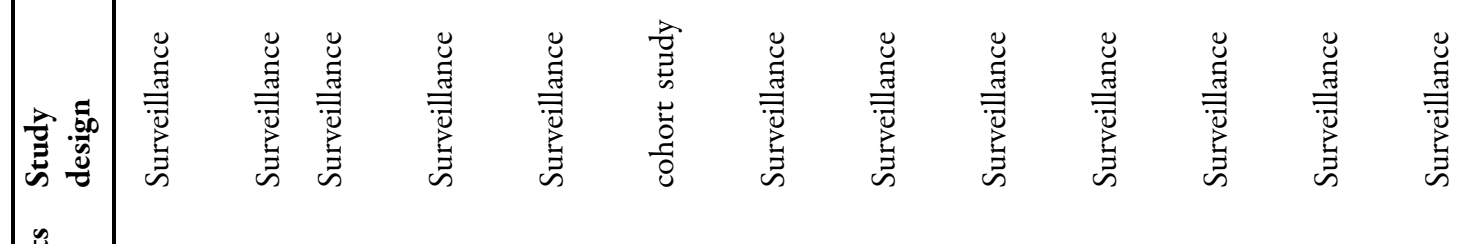

$$
\begin{aligned}
& \text { |气 }
\end{aligned}
$$

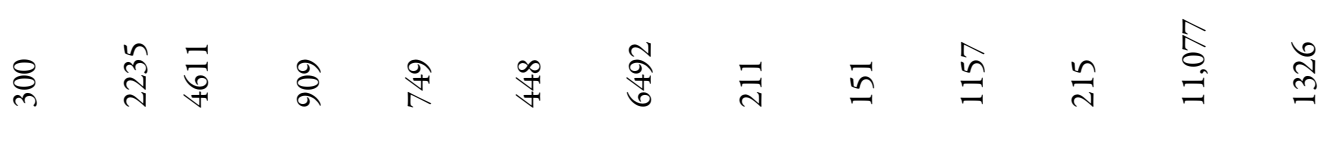

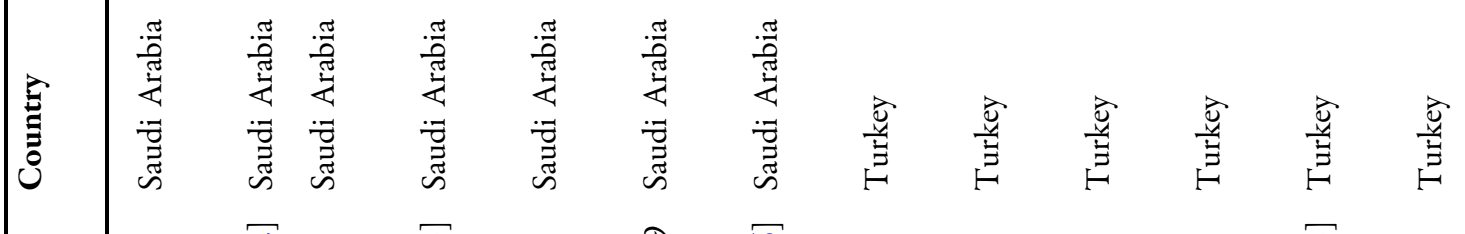

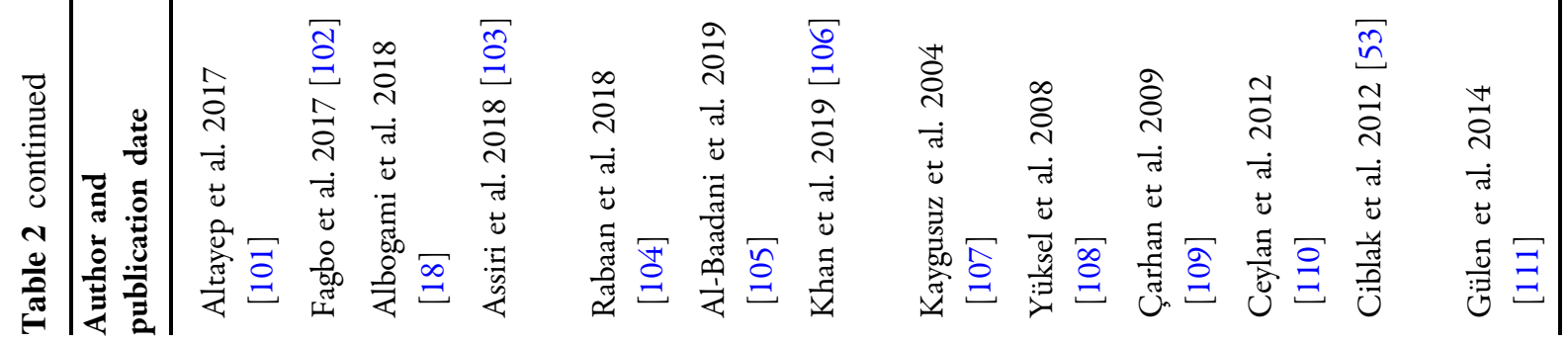




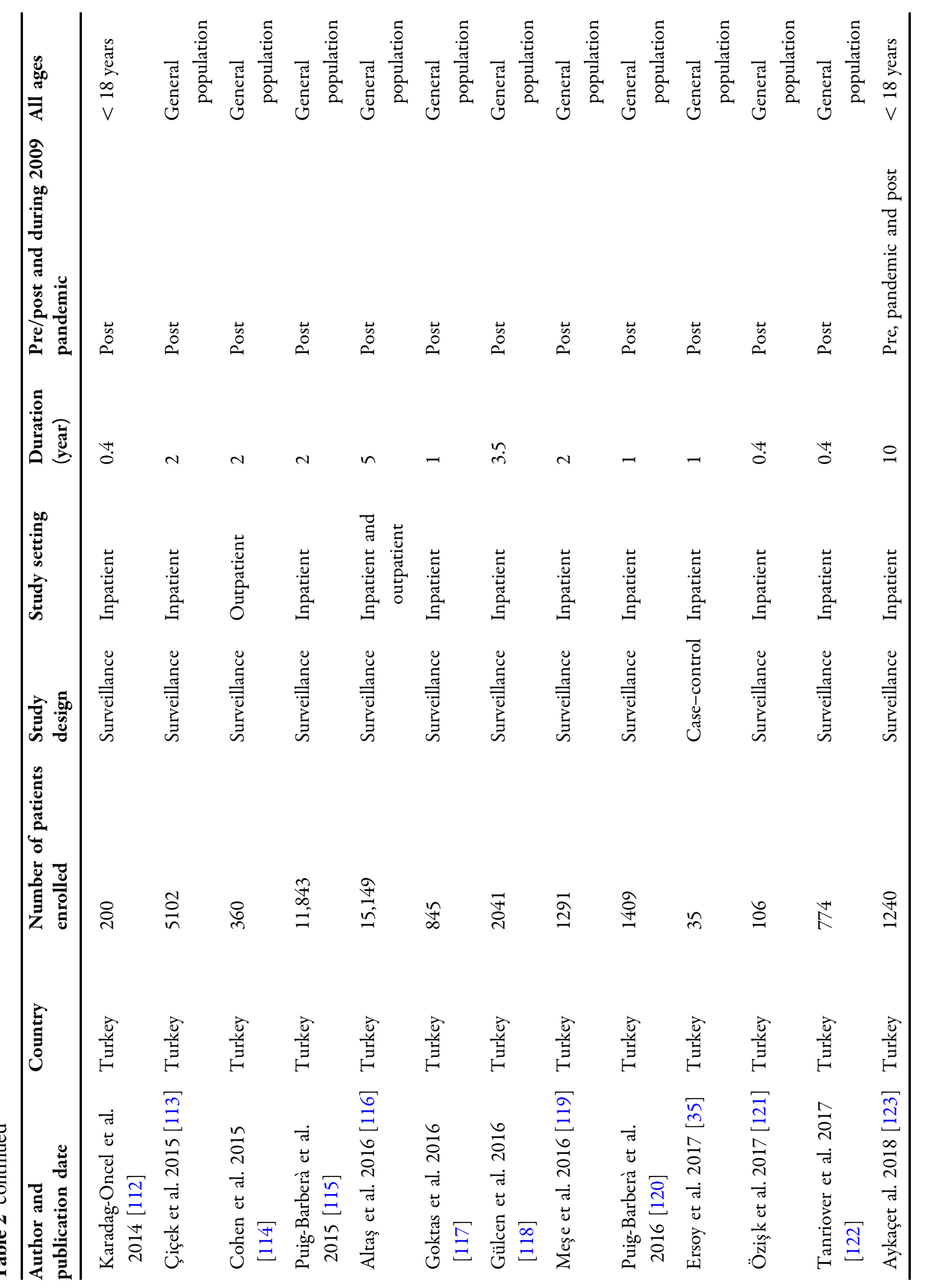




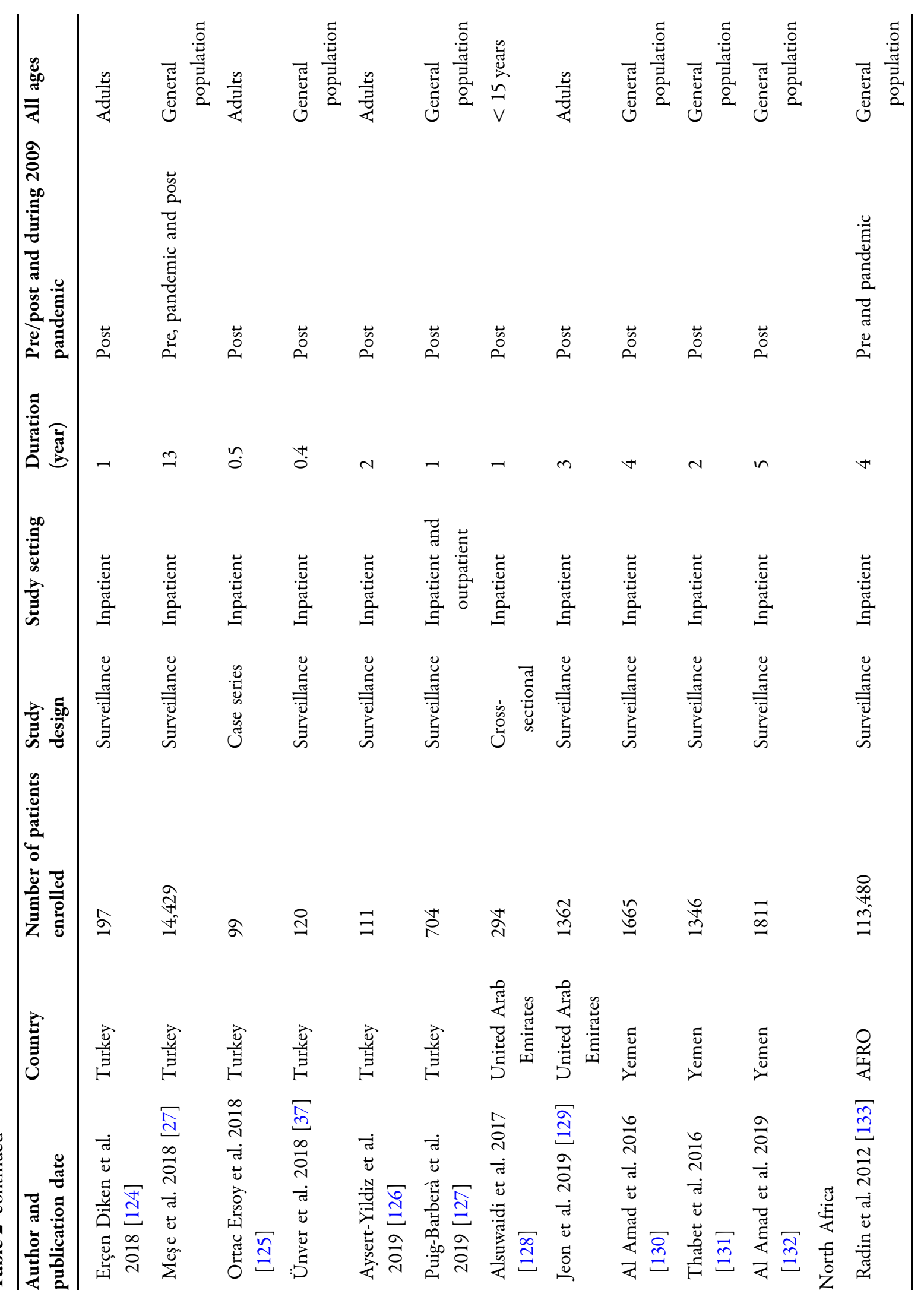




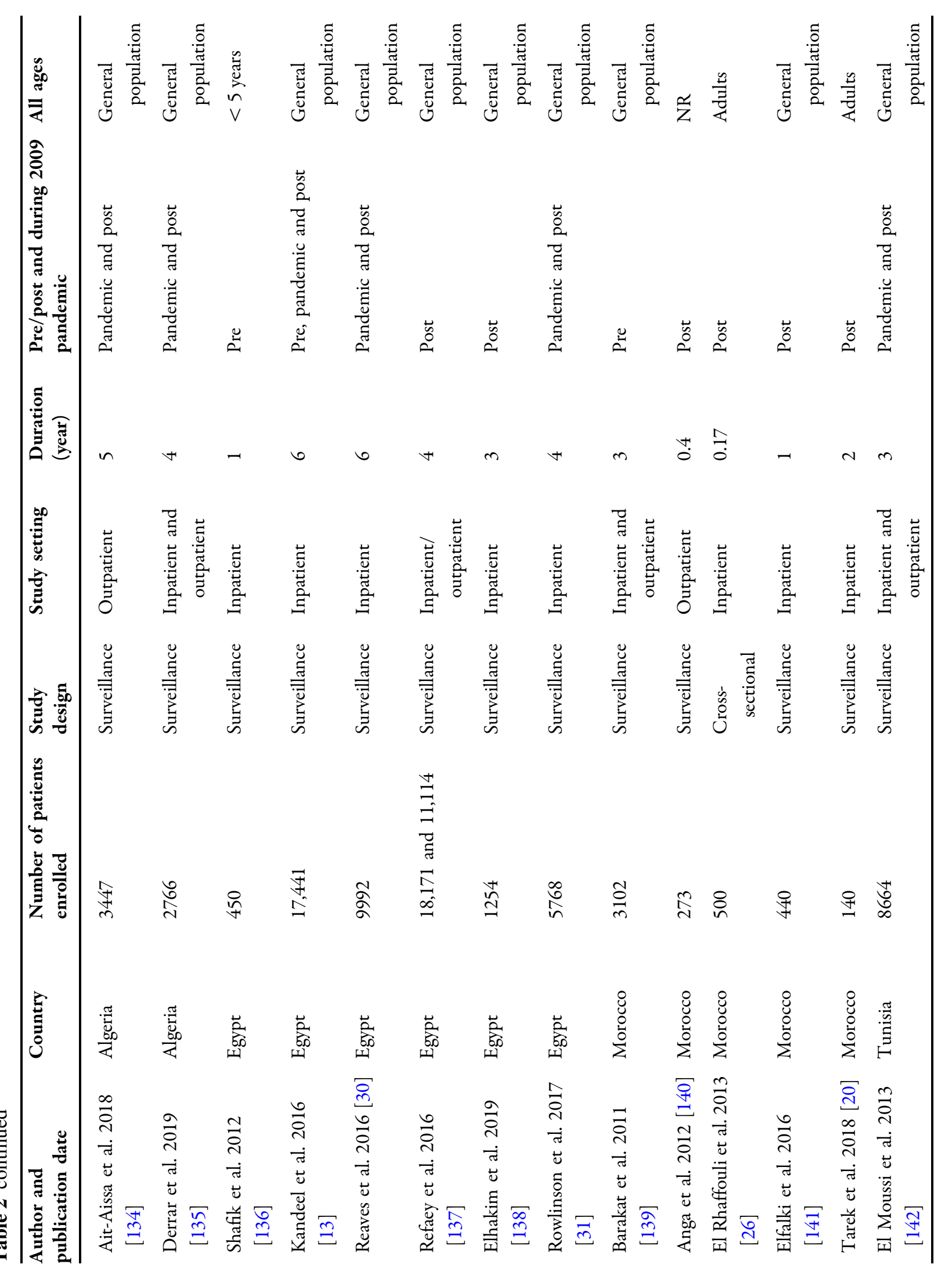




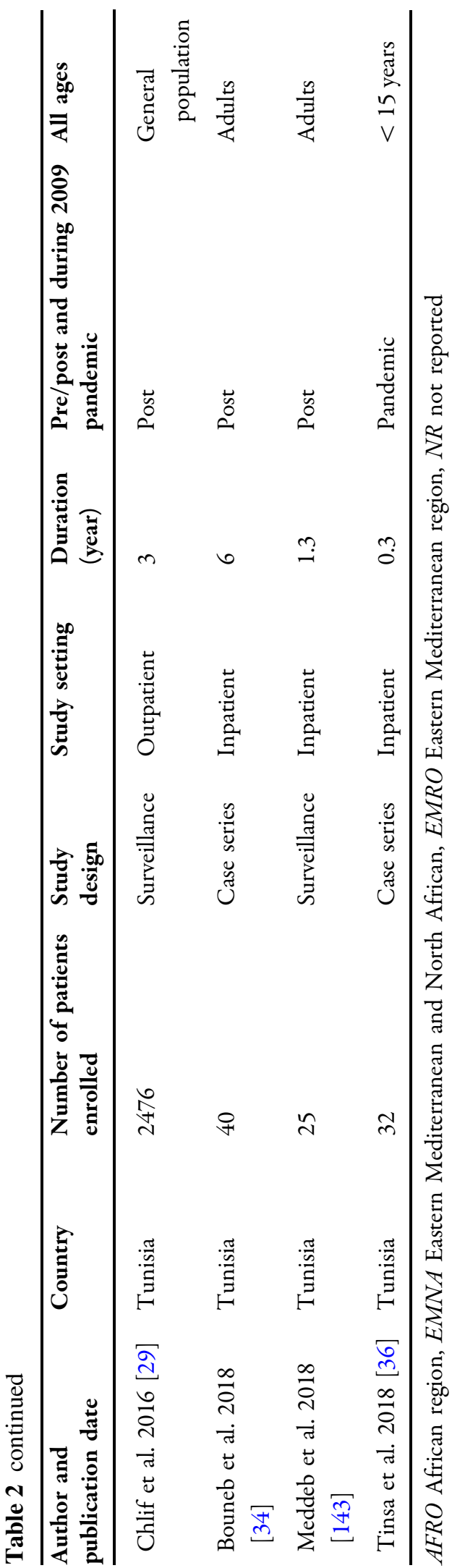

influenza was reported in 24 studies; 18 studies reported a patient population (defined as ILI, lower respiratory tract infection [LRTI], SARI or laboratory-confirmed cases) of which more than $20 \%$ who had at least one risk factor.

\section{Study Design and Data Sources}

Surveillance data were the most common source for the selected 112 studies conducted in the EMNA region $(n=96 ; 86 \%)$. Other sources of data included case series $(n=10)$, cross-sectional $(n=2)$, cohort $(n=3)$ and case-control $(n=1)$ studies. The study duration ranged from 1 month to 13 years (median duration 24 months, interquartile range [IQR] 12-46.5 months).

\section{Influenza Reporting}

The data for influenza reporting for the studies conducted in the region are presented in Table 3. Overall, 314,058 laboratory-confirmed influenza cases were identified across all studies. Among surveillance studies, the percentage of positive cases reported ranged from 1\% [18] through to $100 \%[4,19,20]$. Case definitions for influenza surveillance varied across the studies. The most commonly used definition was that of the WHO for ILI $(n=45,40.2 \%)$; other commonly used definitions included the WHO definition for SARI $(n=17,15.2 \%)$ [21] (three case definitions [2.7\%] included both ILI and SARI), laboratory-confirmed cases of influenza $(n=8,7.2 \%)$, patients diagnosed with acute respiratory infections (ARI), and those presenting with upper and acute lower respiratory tract infections (URLI and ALRI) $(n=10,8.9 \%)$.

The reverse transcription polymerase chain reaction (RT-PCR) was the most frequently used method to detect virus $(n=82,73 \%)$. Other methods employed for identification included cell culture, the hemagglutination inhibition test (HIT) and immunofluorescence.

We identified 83 studies that reported the cocirculation of both influenza A and B strains, 26 reporting data on influenza A strain circulation only, and one study reporting on influenza B strain circulation alone. In studies 


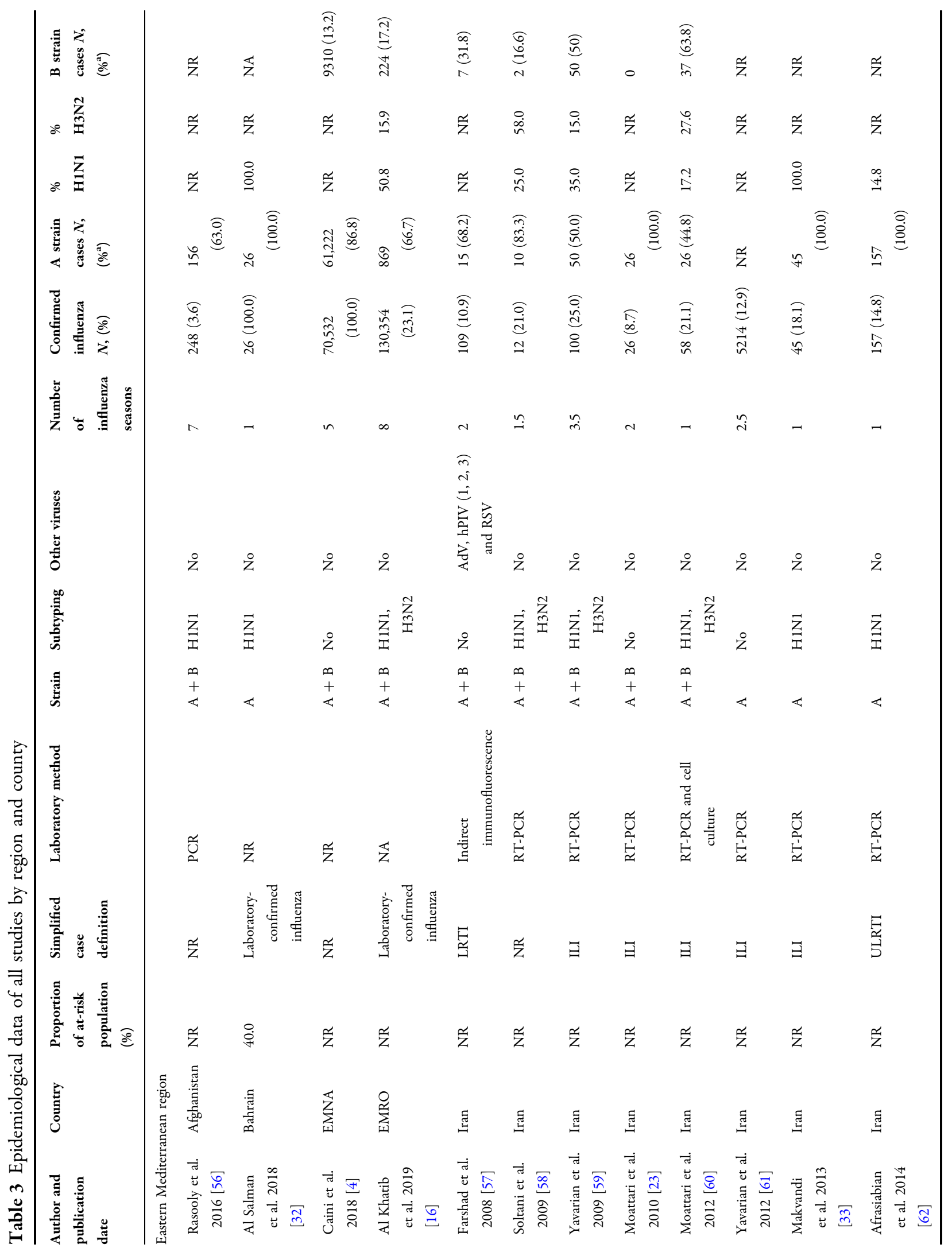




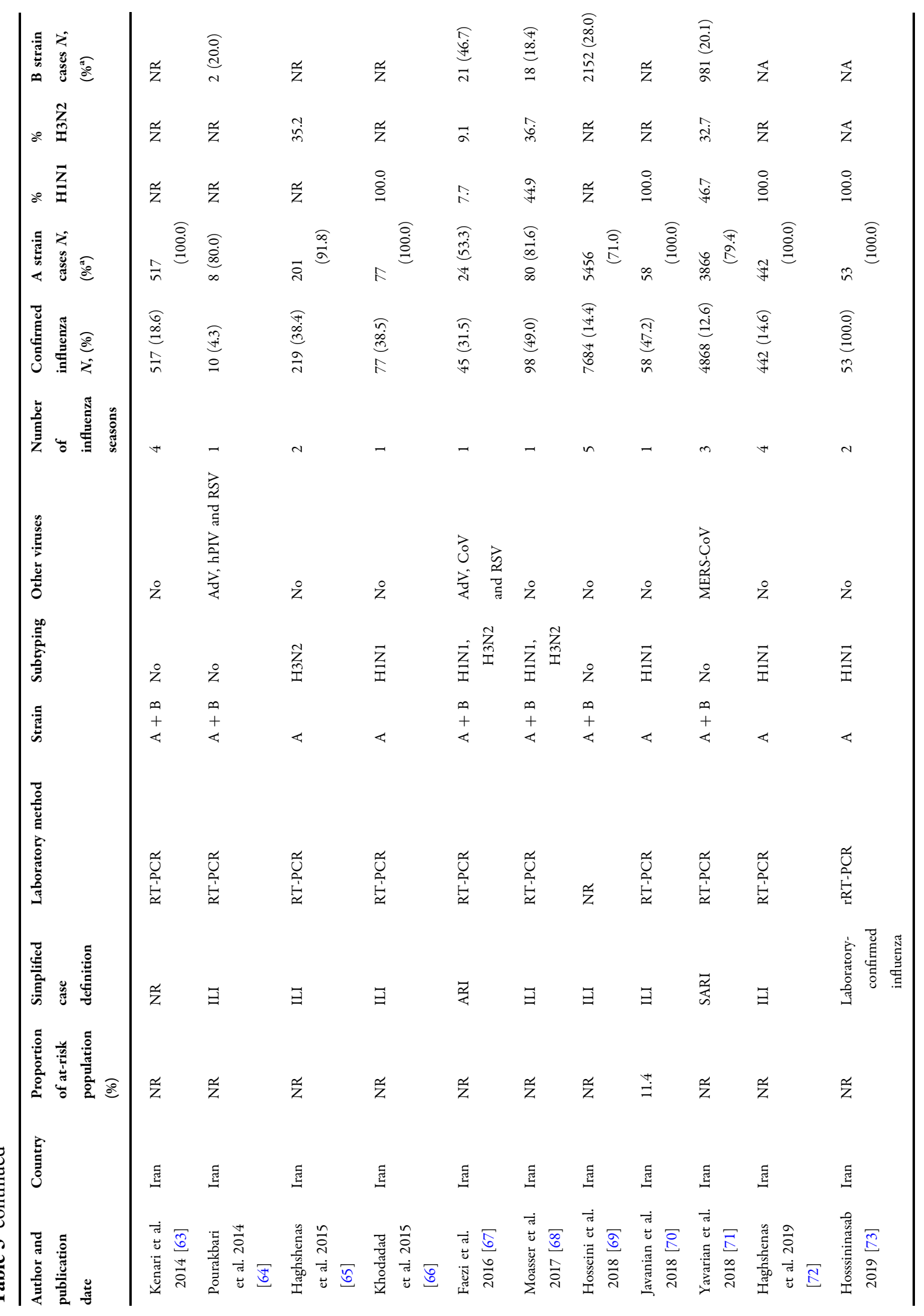




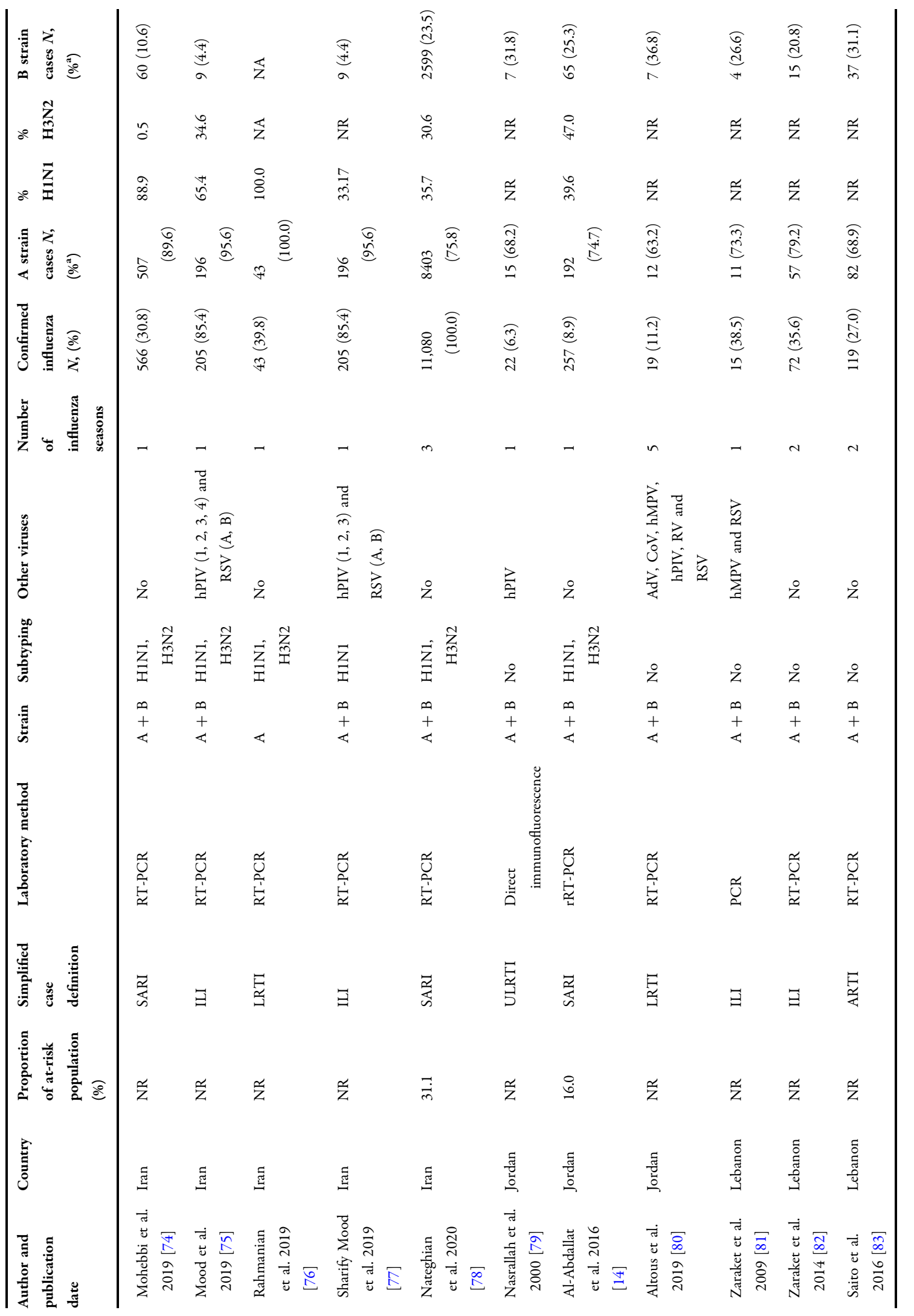




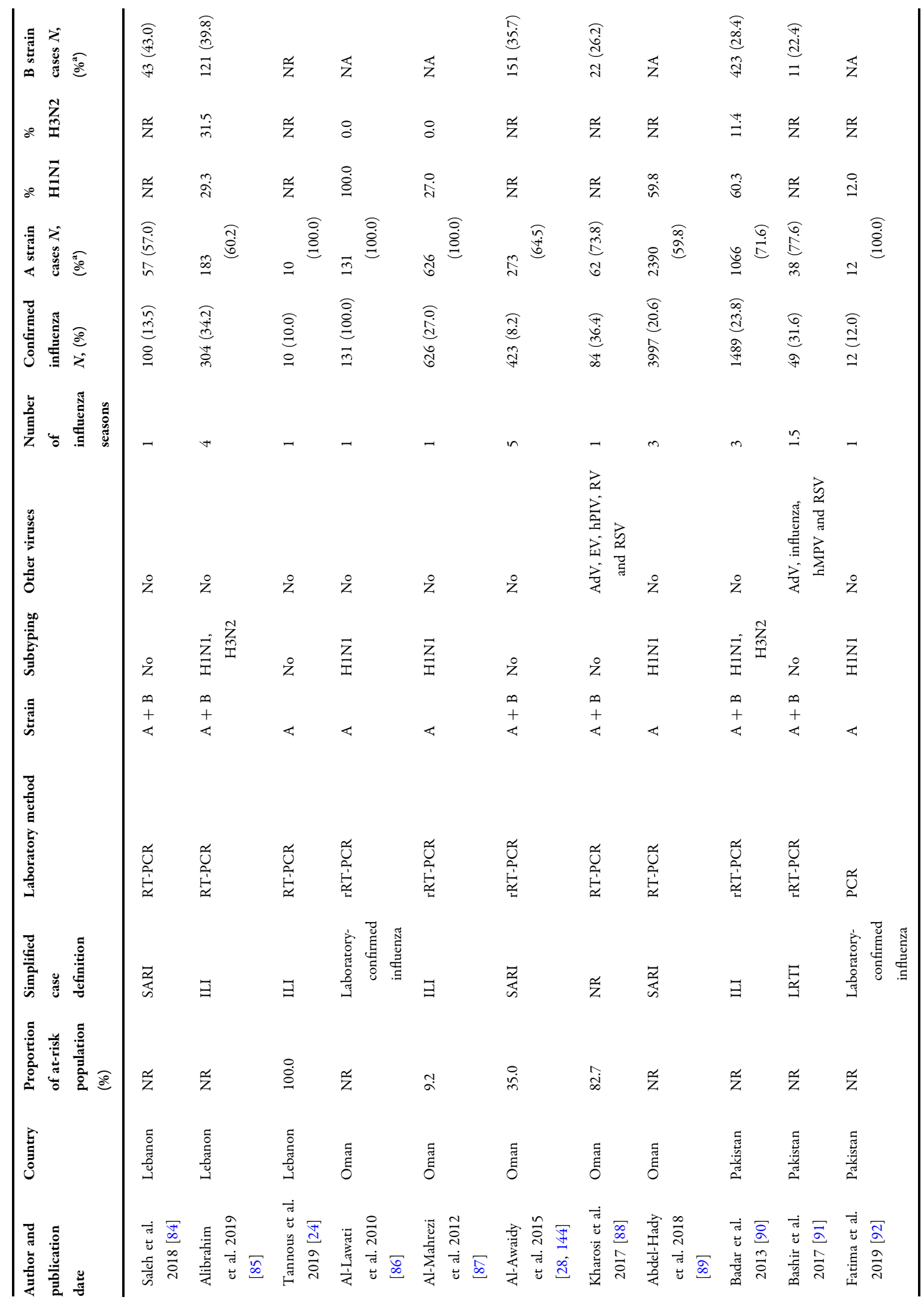




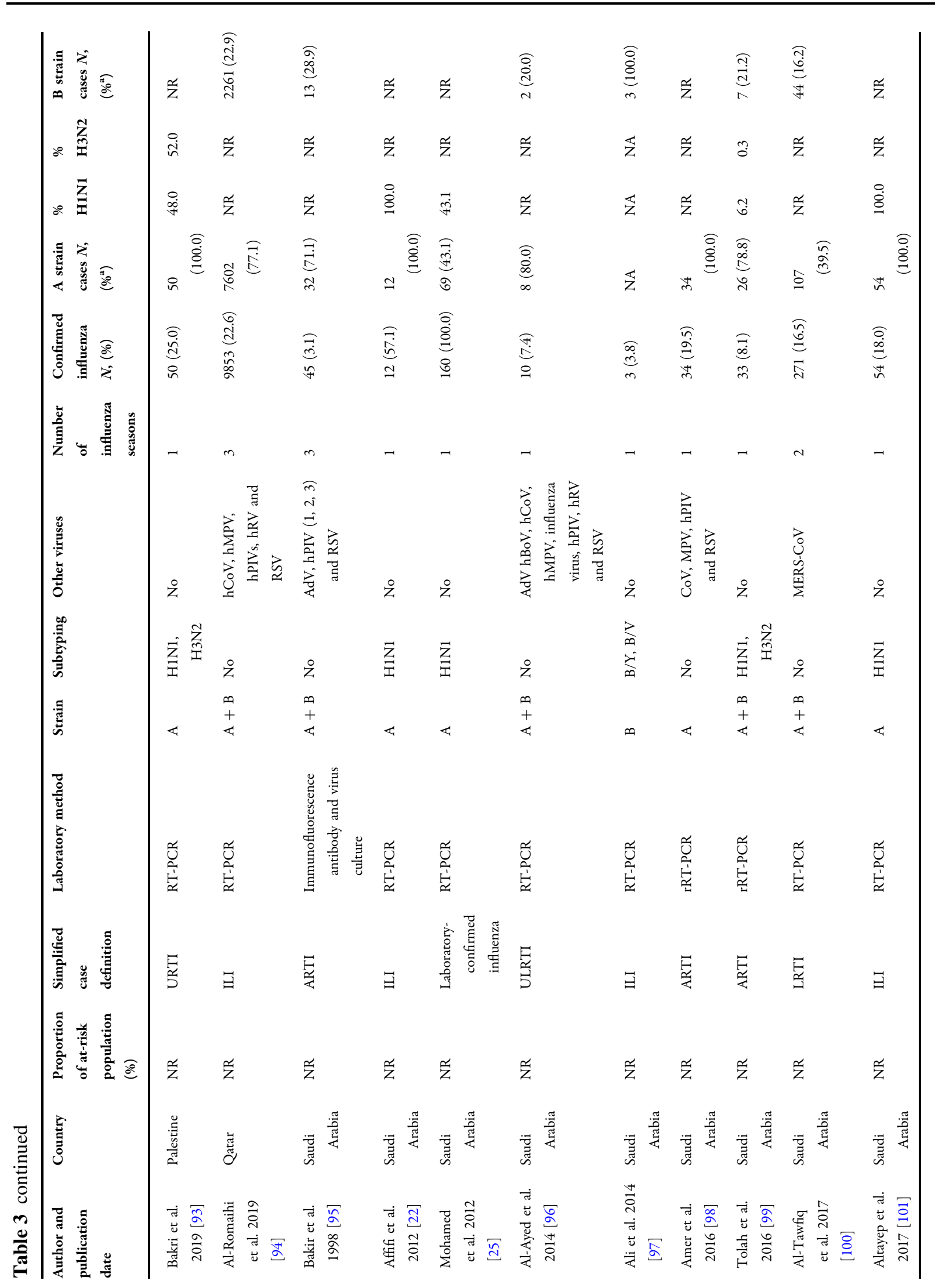




\begin{tabular}{|c|c|c|c|c|c|c|c|c|c|c|c|}
\hline 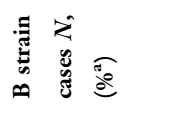 & $\begin{array}{l}\hat{\sigma} \\
\stackrel{+}{*}\end{array}$ & $\begin{array}{l}\infty \\
\stackrel{\infty}{\Xi} \\
a\end{array}$ & $\tilde{z}$ & 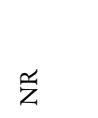 & $\overleftrightarrow{z}$ & $\overleftrightarrow{Z}$ & 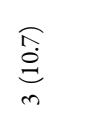 & 牶 & $\begin{array}{l}\widehat{\sigma} \\
\overrightarrow{\tilde{C}} \\
\infty \\
\infty\end{array}$ & $\begin{array}{l}\infty \\
0 \\
\dot{0} \\
\text { in }\end{array}$ & 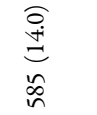 \\
\hline$\stackrel{\tilde{z}}{\tilde{3}}$ & $\tilde{z}$ & $\tilde{z}$ & $\tilde{z}$ & $\tilde{z}$ & $\tilde{z}$ & $\tilde{z}$ & $\tilde{z}$ & $\tilde{z}$ & 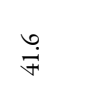 & $\stackrel{\text { i }}{i}$ & 㟔 \\
\hline$\therefore \bar{Z}$ & $\tilde{z}$ & $\tilde{z}$ & $\tilde{z}$ & 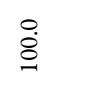 & $\stackrel{\circ}{\vec{F}}$ & $\begin{array}{l}\stackrel{\dot{\Xi}}{0} \\
\text {. }\end{array}$ & $\tilde{z}$ & $\tilde{z}$ & 节 & $\stackrel{m}{=}$ & $\tilde{z}$ \\
\hline 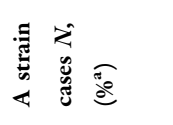 & 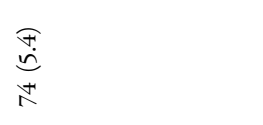 & $\begin{array}{l}\overrightarrow{\overrightarrow{0}} \\
\stackrel{\infty}{\infty} \\
i n\end{array}$ & $\tilde{z}$ & $\stackrel{\grave{\Xi}}{\stackrel{\Xi}{\Xi}}$ & $i_{i=}^{\stackrel{a}{\vec{I}}}$ & 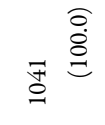 & 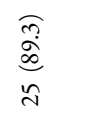 & $\tilde{z}$ & $\underset{\stackrel{\infty}{\infty}}{\stackrel{\widehat{\infty}}{\infty}}$ & $\begin{array}{l}\overparen{\overrightarrow{0}} \\
\stackrel{\oplus}{\infty}\end{array}$ & 吕 \\
\hline 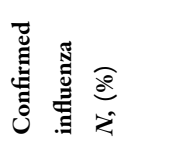 & 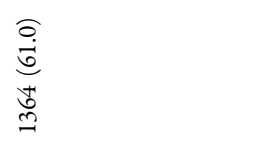 & $\underset{\varpi}{\stackrel{\overbrace{}}{E}}$ & 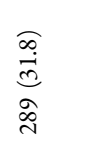 & 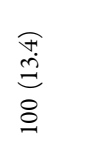 & 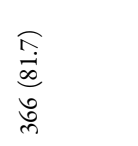 & 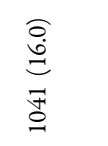 & 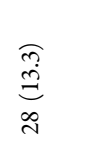 & $\underset{a}{a}$ & 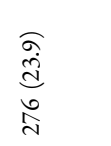 & 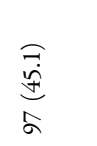 & $\begin{array}{l}\widehat{\infty} \\
\stackrel{0}{0} \\
\stackrel{\infty}{\infty} \\
\neq\end{array}$ \\
\hline 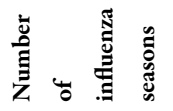 & - & N & - & - & $m$ & - & N & N & - & $m$ & \\
\hline 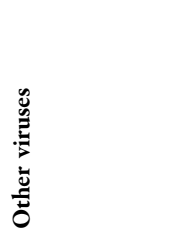 & 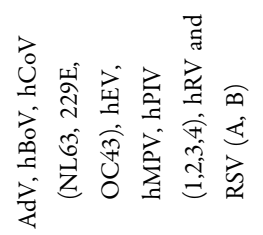 & $\stackrel{2}{Z}$ & z̊ & $\stackrel{2}{Z}$ & 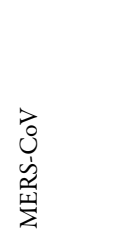 & $\stackrel{2}{Z}$ & 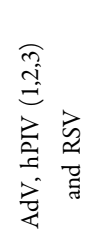 & 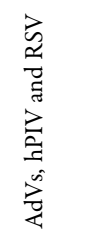 & 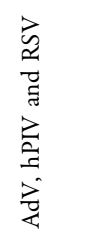 & 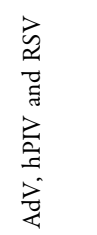 & Z \\
\hline 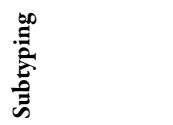 & z̊ & $\stackrel{\circ}{Z}$ & $\stackrel{2}{z}$ & 望 & 禀 & 斈 & z̊ & z̊ & 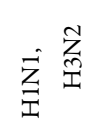 & 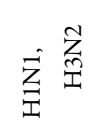 & z̊ \\
\hline 氙 & $\begin{array}{l}\infty \\
+ \\
4\end{array}$ & $\begin{array}{l}\infty \\
+ \\
4\end{array}$ & $\begin{array}{l}m \\
+ \\
4\end{array}$ & $\varangle$ & $\begin{array}{l}\infty \\
+ \\
4\end{array}$ & $\varangle$ & $\begin{array}{l}\infty \\
+ \\
4\end{array}$ & $\tilde{z}$ & $\begin{array}{l}\infty \\
+ \\
4\end{array}$ & $\begin{array}{l}\infty \\
+ \\
4\end{array}$ & $\begin{array}{l}\infty \\
+ \\
4\end{array}$ \\
\hline 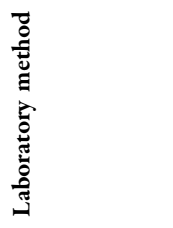 & 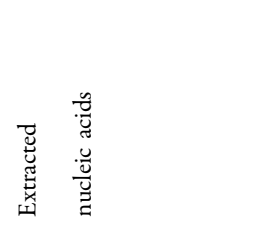 & 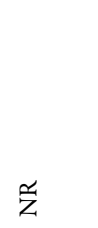 & 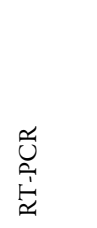 & 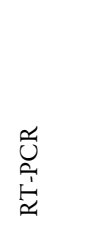 & $\tilde{z}$ & 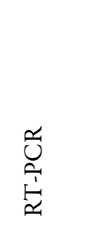 & 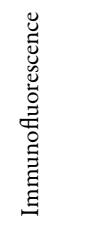 & 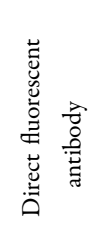 & 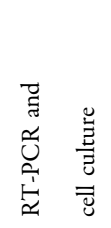 & $\tilde{z}$ & 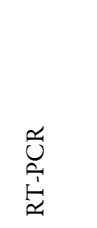 \\
\hline 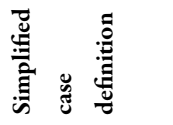 & $\underset{\overrightarrow{2}}{\overrightarrow{4}}$ & $\underset{\mathrm{a}}{\overrightarrow{4}}$ & 丞 & $\vec{E}$ & $\vec{F}$ & $\exists$ & 莺 & $\vec{F}$ & 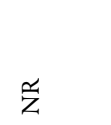 & $\Xi$ & $\exists$ \\
\hline 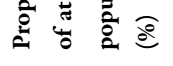 & 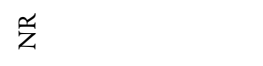 & $\tilde{z}$ & $\tilde{z}$ & 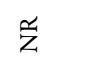 & $\stackrel{m}{i}$ & $\tilde{z}$ & $\tilde{z}$ & $\tilde{z}$ & $\tilde{z}$ & $\tilde{z}$ & $\tilde{z}$ \\
\hline 递 & 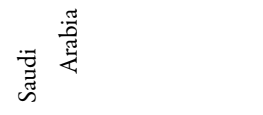 & 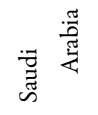 & 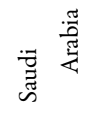 & 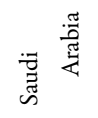 & تृ & 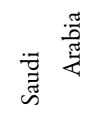 & 章 & 害 & 总 & 蒟 & $\frac{\overrightarrow{\breve{y}}}{\vec{G}}$ \\
\hline 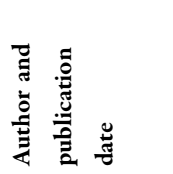 & 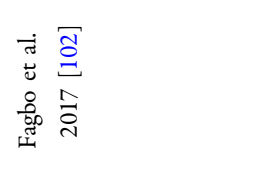 & 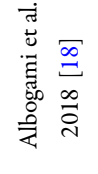 & 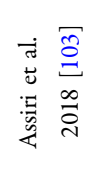 & 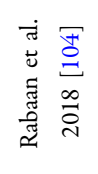 & 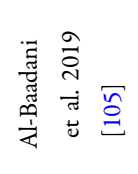 & 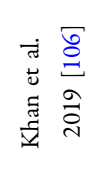 & 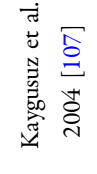 & 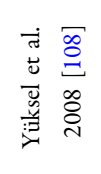 & 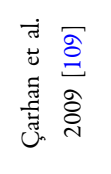 & 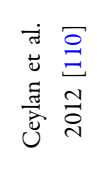 & 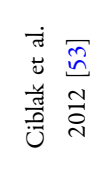 \\
\hline
\end{tabular}




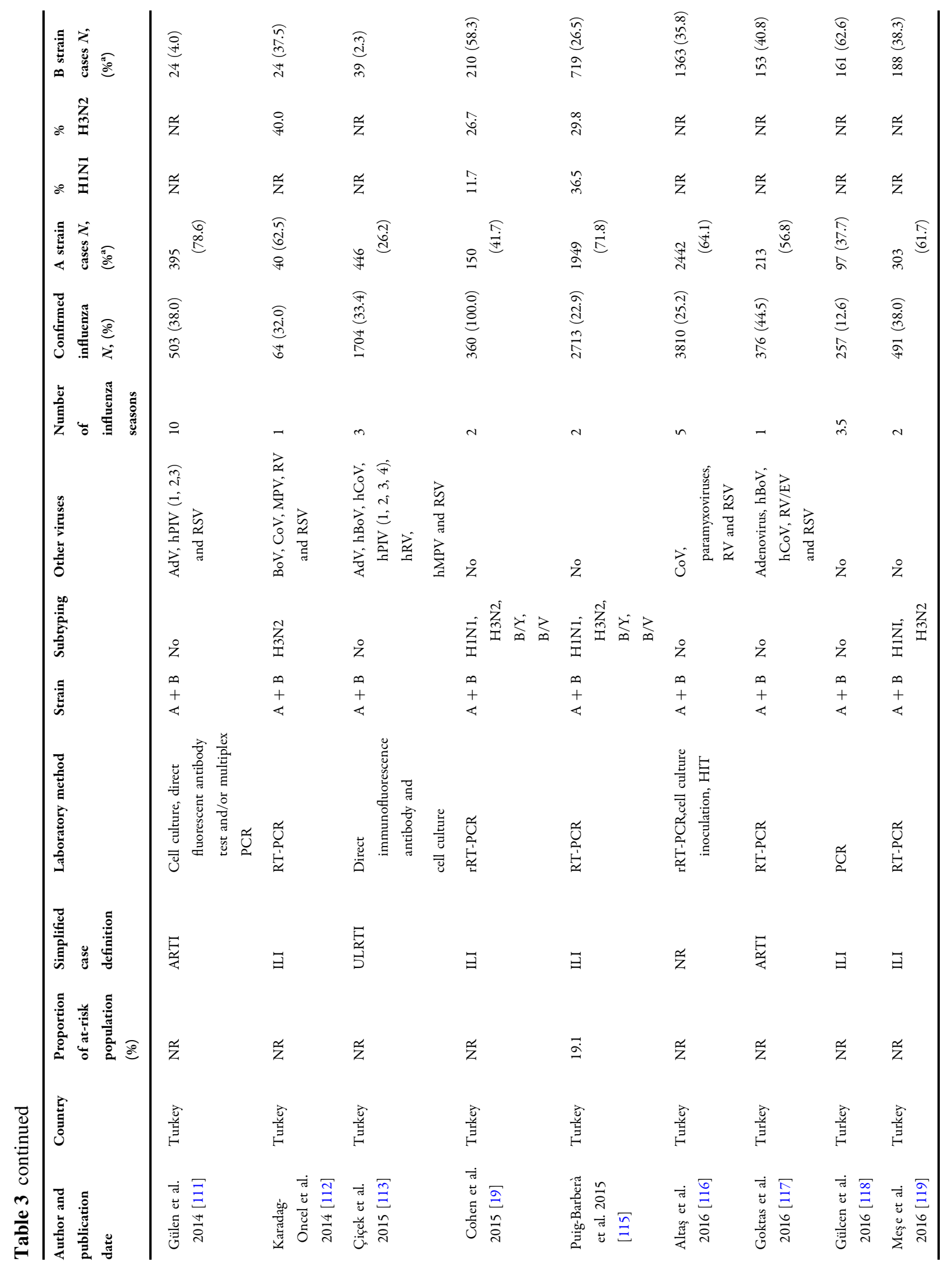




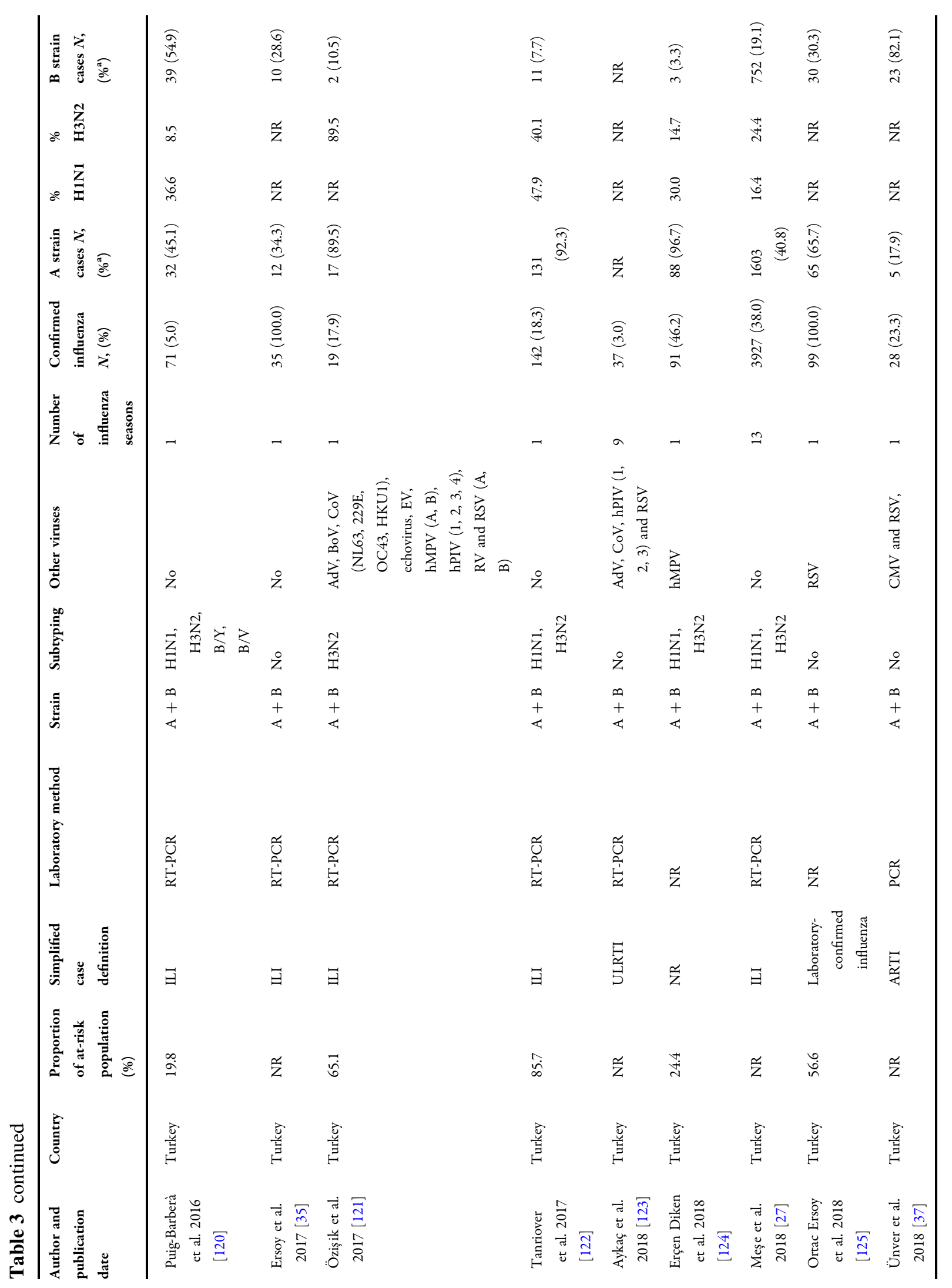




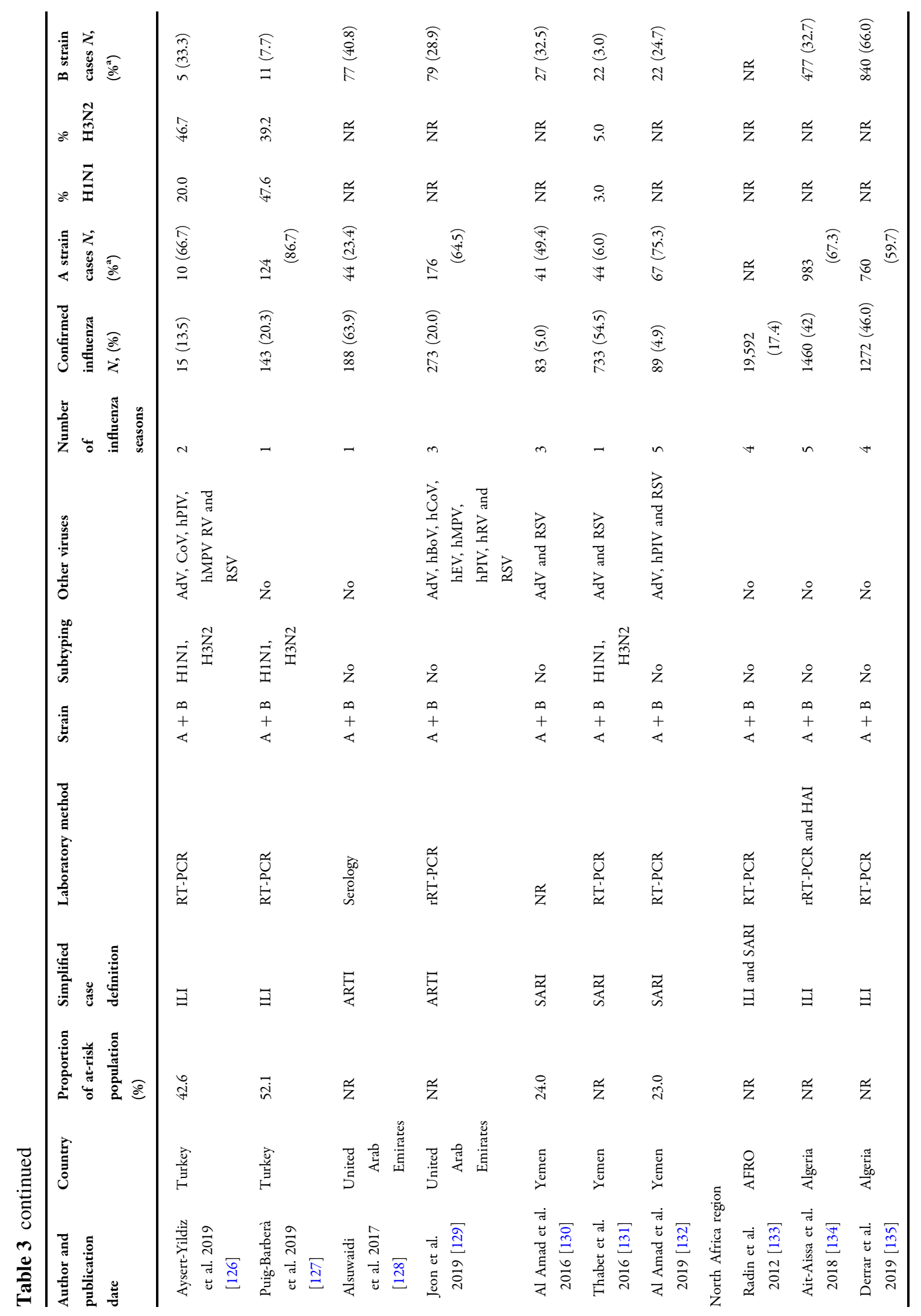




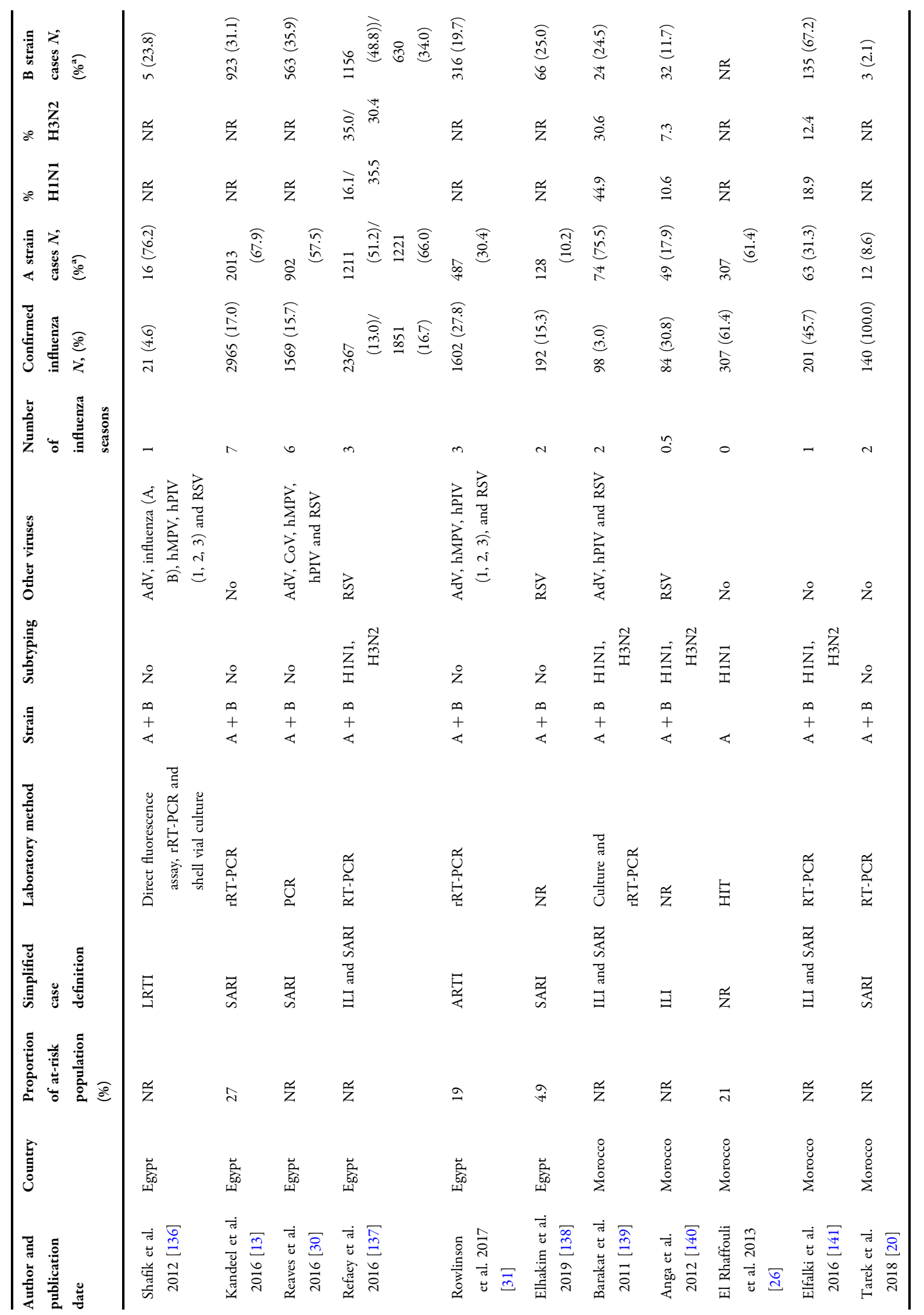




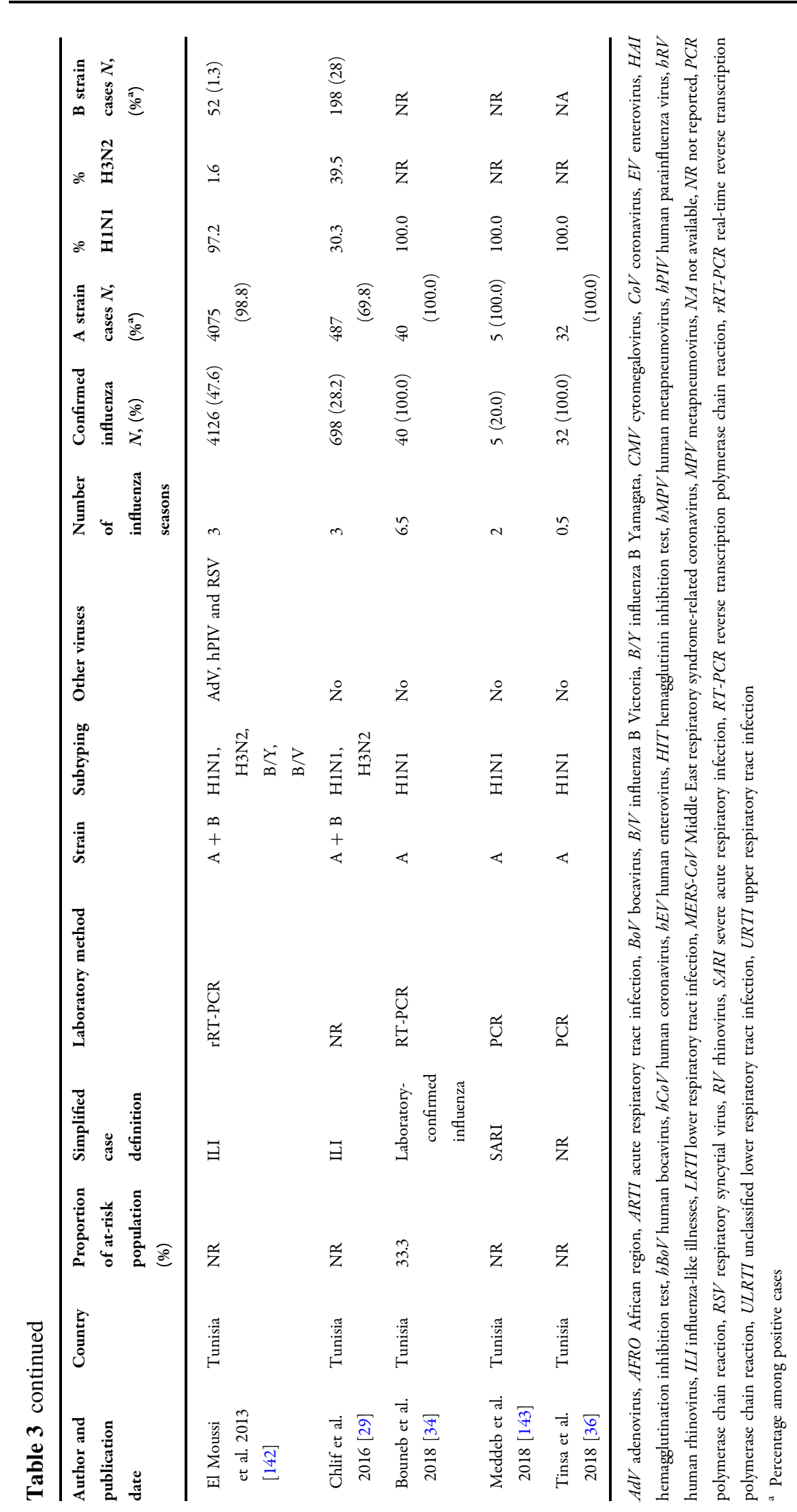




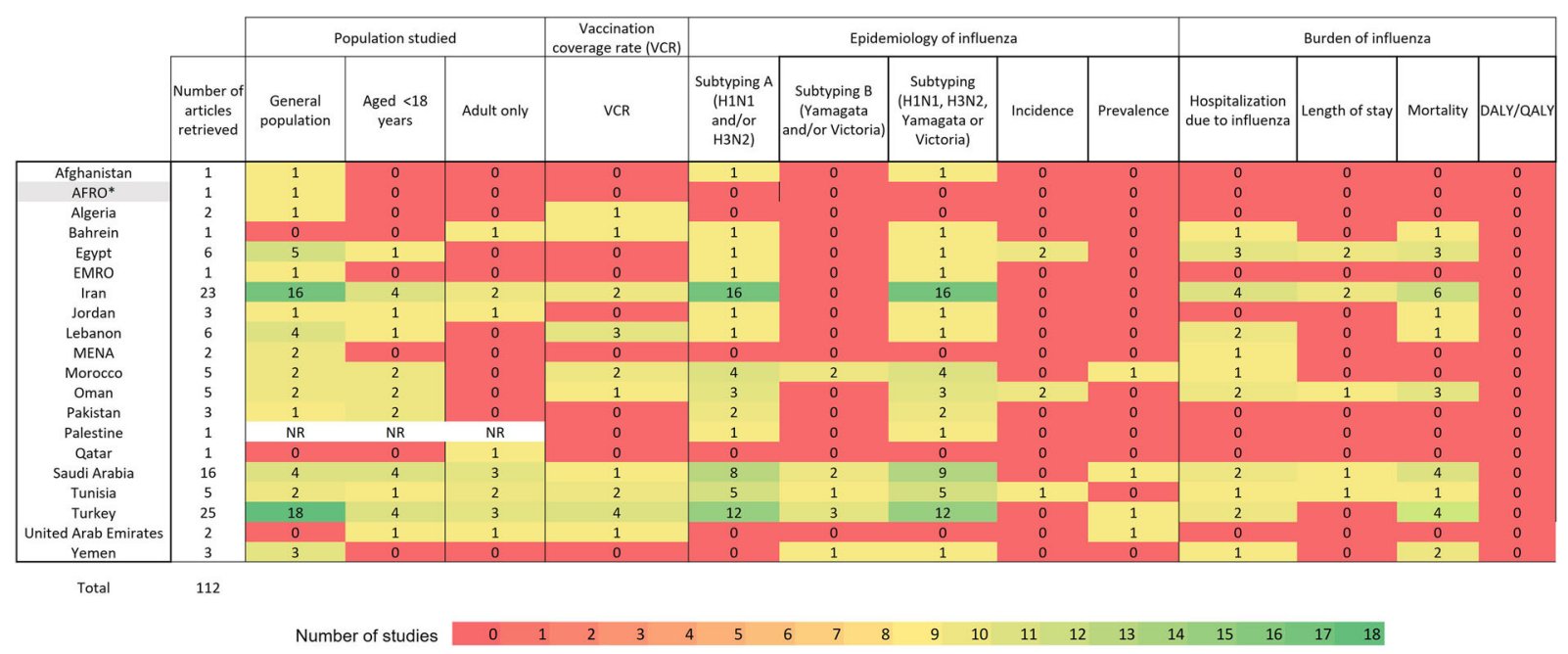

*African countries: only data from Egypt and Morocco were extracted

Fig. 3 Heat map showing number of articles retrieved and availability of data for each country in the EMNA region. *Only data from Egypt and Morocco were extracted

eporting both influenza A and B co-circulation, strain A was the predominantly identified circulating strain. Influenza $A$ and $B$ accounted for a median $67.6 \%$ (IQR $42 \%-86 \%$ ) and $27.0 \%$ (IQR $11 \%-36 \%$ ) of positive cases, respectively. Classification of influenza strain A (H1N1, H3N2) and/or lineage B (Yamagata, Victoria) was performed in half of the studies $(n=58$, $51.2 \%)$. Of these, 47 studies were conducted in the Eastern Mediterranean region, most commonly in Iran $(n=17)$, Turkey $(n=12)$ and Saudi Arabia $(n=8)$. Ten were conducted in North Africa:,most commonly in Tunisia $(n=5)$ and Morocco $(n=4)$ and one study was conducted in both regions. Subtyping of the A strains, H1N1 and H3N2, was undertaken in 57 studies, 21 studies reported data for the H1N1 subtype only and three studies for the H3N2 subtype alone. Only five studies reported data on influenza B lineages and all but one were conducted in the general population. Other viruses were assessed in 46 studies including respiratory syncytial. Other viruses were assessed in 48 studies including respiratory syncytial viruses $(n=34)$, adenoviruses $(n=25)$ and parainfluenza viruses $(n=20)$.

The number of articles reporting on available data for each country are shown in Fig. 3.

\section{Epidemiology}

The number of influenza seasons per study ranged from 0 [22-26] through to 13 [27]. Of those studies reporting zero seasons, four were conducted over the course of 1 month [22-25] and one over 2 months [26].

The median percentage of positive influenza cases reported across the studies was $23.3 \%$ (IQR 1.4-85.5\%). The incidence of influenza was only reported in four studies, all assessing surveillance data in the general population: one study in Oman which evaluated data on inpatients (incidence range $[95 \% \mathrm{CI}]$ from 0.5 [0.1-2.2] to 15.4 [1.1-21.3] per 100,000 population) [28], one study in Tunisia looking at data in outpatients (incidence range across three seasons ranged from 5536 [5457-5615] in $2013 / 14,12,602[12,484-12,722]$ in $2014 / 15$ and $18,735[18,590-18,881]$ in $2012 / 13$ ) per 100,000 population [29] and two studies in Egypt both evaluating data from inpatients (incidence range 96.9/100,000 person-years [30] and 265.2/100,000 population [31]).

Vaccination against influenza was reported in 23 studies, ranging from $0 \%$ [32-36] to $66 \%$ [24] (median 7\%; IQR 2-18\%). However, it should be noted that for four studies reporting $0 \%$ vaccination, one was conducted in 
pregnant women [37], one in children during the 2009 pandemic [36] and one in severely ill patients who were admitted to intensive care [34]. In the general population, the calculated vaccine coverage rate among included suspected cases ranged from $0 \%$ [32] to $66 \%$ (median 7\% [IQR 1-20\%]) [24].

Data on the duration of hospitalisation due to influenza were reported in 11 studies $(9.8 \%)$. Eight of these were conducted in the Eastern Mediterranean region and three in North Africa. Of these, two studies reported data in patients aged less than 15 years, three studies in adults and six studies in the general population. The mean length of stay in hospital ranged between 4 and 23 days (median stay 6 days; IQR 4.4-6.7) in standard and intensive care units.

Information on patients with comorbidities, chronic disorders or considered at high risk of complications as a result of influenza was only reported in 25 studies (22.3\%). Similarly, mortality data as a result of influenza were reported in less than a quarter of the studies $(n=26$; $23.2 \%$ ) and most commonly in the Eastern Mediterranean region, with the highest number of studies reported in Iran $(n=6)$ and Turkey $(n=4)$.

Not all studies looked at specific age populations, some stratified by age group, whereas others looked at the general population $(n=69)$. Eight studies evaluated patients aged less than 5 years age (all laboratory-confirmed cases), eight evaluated patients aged less than 15 years (all but one were laboratory-confirmed cases), four evaluated patients aged less than 18 years (all laboratory-confirmed cases), 18 studies specified the population as adults (all but four were laboratory-confirmed cases) and five did not report the age groups evaluated (all but one were laboratory-confirmed cases).

No studies reported data on disability-adjusted life year (DALY) or quality-adjusted life year (QALY) measures.

\section{CONCLUSION}

We present here a comprehensive, systematic review of the published literature looking at the epidemiology of influenza in the EMNA region over the last 21 years (from 1998 through to 2020). We analysed data from 112 studies, 90 of which were conducted in the Eastern Mediterranean region, 19 in Africa and three across both regions.

Overall, data were reported on 314,058 laboratory-confirmed influenza cases, the majority $(86 \%)$ of which were derived from surveillance systems. Over half the studies (62\%) evaluated data from the general public (paediatric and adult populations combined, across a range of ages or where all age groups were included). Influenza A accounted for a median $67.9 \%$ (IQR $41 \%-89 \%$ ) of all influenza cases in our study, slightly lower than that reported by Caini et al., who assessed influenza surveillance data from the 2010-2016 from the WHO FluNet database and reported a median of $76.5 \%$ (IQR 60.4-90.3\%). Influenza B accounted for a similar proportion of positive cases in our study (23.8\% [IQR 11-36\%]) as that reported in Caini et al. [4] (23.5\% [IQR 9.7\%-39.6\%]) of all influenza cases. In line with Caini et al. [4], we also observed the H1N1 to be the most prominent circulating subtype. Typing was performed in approximately three-quarters and subtyping in only half of the studies we identified, with influenza B strain lineage characterisation only being performed in less than $5 \%$ of the studies we assessed, highlighting a gap for these data in the region. Identifying the virus strain and subtype circulating is important, in order to identify any possible vaccine mismatch, for implementing measures to inform public health interventions to ensure optimal protection of populations.

The number of influenza seasons per study ranged from zero through to 13. Influenza incidence data were not widely reported, only being cited in five studies.

The results of our review also revealed existing gaps in regional estimates of influenza health and economic burden, hospitalisation rates and duration of hospital stay. The absence of influenza disease burden estimates has previously been cited as a reason for a lack of country-level influenza vaccine policies [38].

Given the high prevalence of patients with chronic disease in the EMNA region [2, 3], it is important to collect data on those considered 
most at risk from complications of influenza. These data were reported in only $21 \%$ of the studies we identified. No studies reported measures of quality of life and overall disease burden (i.e. DALY and QALY). Furthermore, data on mortality were reported in less than $24 \%$ of the studies identified. Morbidity and mortality data are important to provide a complete overview of the health burden of disease, which, in turn, is critical to understanding the impact of influenza infections on public health [39]. A lack of knowledge on influenza and its impact with respect to morbidity and mortality has been cited as a major barrier to attaining higher vaccination coverage in the region [40]. Collecting these data in future epidemiological studies may be helpful in informing future public health policies and interventions and help to increase uptake of vaccines.

\section{Strengths and Limitations}

Strengths of our review include the large number of studies included which provide an epidemiological overview of influenza research over the last 21 years across the EMNA region. Furthermore, we systematically searched multiple databases, beyond those reported in the WHO's FluNet, to look for epidemiological data.

Our study also relies on peer-reviewed and published data which provides more reliability and confidence on the data and findings, in comparison to other databases such as FluNet. However, it is possible that we may have not captured some data with the search strategy we implemented. Such databases tend to focus on virological surveillance data in the Eastern Mediterranean and African region WHO regions (though some countries also report the burden of disease data), and the aim of this review was to provide an overview of the epidemiology and burden of influenza disease. In addition, differences in clinical assessment, application of case definitions and laboratory assessment of influenza testing (including sampling methods) make data comparisons across countries difficult to perform. Furthermore, FluNet is limited by the quality of the data submitted (as a consequence of adherence to and robustness of the methods used by the reporting country or centre), underreporting and misclassification are not uncommon, and the large variability in reporting between years by some countries may mean influenza estimates are based on limited data. Mixed-season influenza activity may mean data are oversimplified in large and geographically diverse countries where influenza activity is summarised countrywide [41].

In recent years, the epidemiology of influenza and disease burden has been assessed in single countries in the EMNA region [13-15]; however, studies across the whole region are lacking. A previous literature review, looking at how influenza had changed in the region from 2012 through to 2016, identified a limited number of publications on epidemiology of the disease, concluding that, although virus surveillance had increased, data were still needed, particularly on burden of disease [42]. More recently, Moghoofei et al. [43] conducted a systematic literature review assessing influenza A prevalence across 17 countries within the region. In common with our results, the majority of studies assessed virus in the general population, rather than a specific age group, and the most frequently used method to detect virus was PCR-based, with the most commonly identified subtype being the H1N1 strain. The pooled estimation of the influenza prevalence was reported to be $10.2 \%$, albeit with much variation across the populations studied. We did not undertake a meta-analysis to estimate prevalence rate in our study owing to the large heterogeneity in methodology across studies. Unlike Moghoofei et al., we did not restrict our searches to influenza $\mathrm{A}$ and thus our review provides a broader picture of the influenza landscape across the EMNA region, including reporting for the influenza B strain. A summary of the epidemiological and characterisation of H1N1 and H3N2 strains of the influenza virus circulating in the EMNA region from 2009 to 2017 was also recently published by Al Khatib et al. [16]. Using virological surveillance data available from the FluNet database, the authors assessed data from 16 countries within the region; Saudi Arabia, Yemen and Libya were not included as data were not available. In line with that reported by Moghoofei et al. [43] and our 
own results, $\mathrm{Al}$ Khatib et al. also reported that the influenza strain A H1N1 was, in general, the dominant subtype reported across the region. The study also estimated the epidemiology of influenza type B in the region, which accounted for $20.5 \%$ of influenza cases, higher than the $17.2 \%$ reported in our study. This difference may have been a result of $\mathrm{Al}$ Khatib et al., assessing data from FluNet, whereas our study looked at data from published studies only.

In line with the results reported in our study for the EMNA region, analysis of data at both the global and regional levels shows a predominance of influenza A compared to influenza B [44-46]. For instance, reports from the Global Influenza Hospital Surveillance Network show a predominance of influenza A with a prevalence greater than $60 \%$ and influenza $B$ accounting for 21-34\% between 2014 and 2017 [46, 47]. A systematic review by Tokars et al. [45] estimated the incidence of influenza $A$ and $B$ from surveillance data of the general population in the USA and Canada between 2010 and 2017 to be $7.1 \%$ (95\% CI 6.1-8.1), which is in broad agreement with the incidence data presented in this review.

A large epidemiological study conducted in 31 countries looking at epidemiological characteristics, pattern of circulation and geographical distribution of influenza B viruses using data from the Global Influenza B Study showed that they accounted for a median of $23.4 \%$ of total influenza cases between 2000 and 2018 [44], higher than that reported in our study. Again, this may be a result of our study looking at published data only, whereas the data from the Global Influenza B Study were database-derived. A systematic review looking at a global analysis of the epidemiology of influenza B virus found the frequency ranged from 0 to $40.6 \%$ across six studies from the USA and from $1.6 \%$ to $24.4 \%$ across four studies in Europe [48]. Variability in the way the data were collected makes it difficult to compare with the influenza B data reported in our review. A more in-depth comparison of the epidemiological patterns of influenza between the EMNA region and other geographical areas would be an interesting focus that will help tailor prevention and vaccination strategies.

\section{Current Landscape}

The EMNA region is geographically contiguous, making it an important region for influenza circulation surveillance. The availability of influenza data in the region has improved since the 2009 pandemic. The WHO has implemented a number of strategies across the EMNA region, including strengthening surveillance (with 15 countries reporting on ILI/SARI, or both) and improving knowledge of the burden of influenza [44]. Although the majority of countries in the region now have some form of influenza surveillance in place [45], they still face multiple challenges in introducing or expanding influenza surveillance, prevention and control programmes [46]. Encouragingly, laboratory detection, influenza disease burden estimation and use of seasonal influenza vaccines for influenza control are also increasing [45], although the approach to clinical and laboratory assessment and case definitions is not yet standardised.

A recent review, looking at seasonal influenza vaccination in 11 countries within the region, highlighted substantial research gaps and major disparities across countries [47]. Despite recommendations on influenza vaccination, attaining high vaccine coverage rates continues to be a challenge in the WHO Eastern Mediterranean region $[40,48]$.

The increase in the number of publications and research around influenza since the 2009 pandemic is encouraging and suggests an increase in awareness around influenza and the importance of reducing its burden. However, much work remains to be done. The heterogeneity in assessment and data collection across the region makes surveillance comparisons difficult. Implementation of regional standardisation would allow direct data comparisons and help in understanding the impact of influenza in the region. In addition to studying existing influenza virus strains, it is extremely important to be alert to any new emerging subtypes as well possible changes in virulence or transmission of new infections to the region; for instance, Egypt and Oman are the first countries outside of eastern and southern Asia to report human infection of H9N2 [49]. 
Finally, for the purposes of this review, we evaluated the literature up to and including January 2020 and did not evaluate the literature beyond this date in order to avoid potential implications on epidemiology as a consequence of the COVID-19 pandemic.

Current influenza surveillance data will be confounded, to varying extents, by the COVID19 pandemic and the public health measures implemented by most countries to suppress COVID-19 transmission, including social distancing, hand hygiene and wearing of face masks, all of which may impact the circulation or transmission of influenza. The WHO reports that, in some countries, influenza activity is at lower than expected levels [50]. However, influenza data during the COVID-19 pandemic should be treated with caution and any subsequent analyses should account for resultant confounding.

Despite the improvement of influenza surveillance following the 2009 pandemic, many opportunities remain unexplored in the EMNA region. Data gaps are still substantial, including subtyping and vaccine coverage rates. Notable work is underway to fill these gaps, such as the initiatives being undertaken by the EMARIS network [11], but strengthening regional research is still needed for a better understanding of influenza epidemiology and to improve epidemic and pandemic response. Disease burden estimates, or studies evaluating the impact of vaccine data on reducing the risk or burden of influenza, play a crucial role in helping to address the threat of seasonal influenza and ensure adequate vaccination coverage. Our results highlight the need for robust and high-quality epidemiology data to inform policy and refine public health interventions. Although global and international efforts to collect virological data on influenza circulation are undertaken by the WHO and other health organisations, data reporting varies hugely across counties and sites.

\section{ACKNOWLEDGEMENTS}

Funding. This study was funded by Sanofi Pasteur, who are also funding the journal's Rapid Service Fees.

Medical Writing Assistance. The authors would like to thank Aneela Majid, PhD, from HealthCare21 Communications Ltd, Macclesfield, Cheshire, SK10 2XA, UK, a Lucid Group agency, for providing medical writing support which was funded by Sanofi Pasteur.

Authorship. All named authors meet the International Committee of Medical Journal Editors (ICMJE) criteria for authorship for this article, take responsibility for the integrity of the work as a whole, and have given their approval for this version to be published.

Author Contributions. AA and SS performed the literature search and data analysis. GD was also involved in the analysis and interpretation of data. S Soudani, A Mafi, Z Al Mayahi , S Al Balushi , G Dbaibo, S Al Awaidy and A Amiche drafted and/or critically revised the work.

Disclosures. Amine Amiche, Alireza Mafi and Samira Soudani are employees of Sanofi Pasteur and may hold shares and/or stock options in the company. Ghassan Dbaibo received grant funding through his institution from Pfizer and Sanofi Pasteur for unrelated work and honoraria for advisory board participation and lectures from MSD, Pfizer and Sanofi. Zayid Al Mayahi, Sultan Al Balushi and Salah Al Awaidy have nothing to disclose.

Compliance with Ethics Guidelines. This article is based on previously conducted studies and does not contain any new studies with human participants or animals performed by any of the authors.

Open Access. This article is licensed under a Creative Commons Attribution-NonCommercial 4.0 International License, which permits any non-commercial use, sharing, adaptation, distribution and reproduction in any medium 
or format, as long as you give appropriate credit to the original author(s) and the source, provide a link to the Creative Commons licence, and indicate if changes were made. The images or other third party material in this article are included in the article's Creative Commons licence, unless indicated otherwise in a credit line to the material. If material is not included in the article's Creative Commons licence and your intended use is not permitted by statutory regulation or exceeds the permitted use, you will need to obtain permission directly from the copyright holder. To view a copy of this licence, visit http://creativecommons.org/licenses/by$\mathrm{nc} / 4.0 /$.

\section{REFERENCES}

1. World Health Organization. Global influenza strategy. 2020. https://www.who.int/news/item/11-032019-who-launches-new-global-influenza-strategy. Accessed 3 Nov 2020.

2. World Health Organization. Influenza (Seasonal). Fact sheet. 2020. https://www.who.int/news-room/ fact-sheets/detail/influenza-(seasonal). Accessed 30 Nov 2020.

3. Luliano AD, Roguski KM, Chang HH, et al. Estimates of global seasonal influenza-associated respiratory mortality: a modelling study. Lancet. 2018;391:1285-300.

4. Caini S, El-Guerche Séblain C, Ciblak MA, Paget J. Epidemiology of seasonal influenza in the Middle East and North Africa regions, 2010-2016: circulating influenza $A$ and $B$ viruses and spatial timing of epidemics. Influenza Other Respir Viruses. 2018;12: 344-52.

5. Fiore AE, Shay DK, Broder K, et al. Prevention and control of seasonal influenza with vaccines: recommendations of the Advisory Committee on Immunization Practices (ACIP), 2009. MMWR Recommend Rep. 2009;58:1-52.

6. Lim SS, Vos T, Flaxman AD, et al. A comparative risk assessment of burden of disease and injury attributable to 67 risk factors and risk factor clusters in 21 regions, 1990-2010: a systematic analysis for the Global Burden of Disease Study 2010. Lancet. 2012;380:2224-60.

7. Ben Abdallah FC, Taktak S, Chtourou A, Mahouachi $\mathrm{R}$, Kheder $\mathrm{AB}$. Burden of chronic respiratory diseases
(CRD) in Middle East and North Africa (MENA). World Allergy Org J. 2011;4:S6-8.

8. Macias AE, McElhaney JE, Chaves SS, et al. The disease burden of influenza beyond respiratory illness. Vaccine. 2021;39 Suppl 1:A6-A14.

9. Krammer F, Smith GJD, Fouchier RAM, et al. Influenza. Nat Rev Dis Primers. 2018;4:3.

10. Enhancing influenza surveillance in the Eastern Mediterranean Region: Eastern Mediterranean Acute Respiratory Infection Surveillance (EMARIS) network-third inter-country meeting. East Mediterr Health J. 2016;22:560-1.

11. Abubakar A, Barakat A, Ahmed A, et al. Fourth meeting of the Eastern Mediterranean Acute Respiratory Infection Surveillance (EMARIS) network and first scientific conference on acute respiratory infections in the Eastern Mediterranean Region, 11-14 December, 2017, Amman, Jordan. J Infect Public Health. 2020;13:451-6.

12. World Health Organization. Influenza. Global influenza surveillance and response system (GISRS). FluNet. 2020. https://www.who.int/influenza/gisrs laboratory/flunet/en/. Accessed 02 Nov 2020.

13. Kandeel A, Dawson P, Labib M, et al. Morbidity, mortality, and seasonality of influenza hospitalizations in Egypt, November 2007-November 2014. PLoS ONE. 2016;11:e0161301-e.

14. Al-Abdallat $M$, Dawson $\mathrm{P}$, Haddadin AJ, et al. Influenza hospitalization epidemiology from a severe acute respiratory infection surveillance system in Jordan, January 2008-February 2014. Influenza Other Respir Viruses. 2016;10:91-7.

15. Gouya M, Rezaei F, Haghdoost A, et al. Estimation of influenza and severe acute respiratory illness incidence (burden) in three provinces of the Islamic Republic of Iran, 2012 and 2013. East Mediterr Health J. 2016;22:432-9.

16. Al Khatib HA, Al Thani AA, Gallouzi I, Yassine HM. Epidemiological and genetic characterization of pH1N1 and H3N2 influenza viruses circulated in MENA region during 2009-2017. BMC Infect Dis. 2019;19:314.

17. Elhakim M, Hafiz Rasooly M, Fahim M, et al. Epidemiology of severe cases of influenza and other acute respiratory infections in the Eastern Mediterranean Region, July 2016 to June 2018. J Infect Public Health. 2020;13:423-9.

18. Albogami SS, Alotaibi MR, Alsahli SA, Masuadi E, Alshaalan M. Seasonal variations of respiratory viruses detected from children with respiratory tract 
infections in Riyadh, Saudi Arabia. J Infect Public Health. 2018;11:183-6.

19. Cohen JM, Silva ML, Caini S, et al. Striking similarities in the presentation and duration of illness of influenza A and B in the community: a study based on sentinel surveillance networks in France and Turkey, 2010-2012. PLoS ONE. 2015;10:e0139431.

20. Tarek D, Imad C, Imane E, et al. Severe acute respiratory infections of viral origin in Moroccan medical ICU: Incidence and prognostic factors. Ann Intensive Care. 2018;2018:8.

21. World Health Organization. WHO surveillance case definitions for ILI and SARI. 2020. https://www. who.int/influenza/surveillance_monitoring/ili_ sari_surveillance_case_definition/en/. Accessed 30 Oct 2020.

22. Affifi RM, Omar SRA. A novel influenza A (H1N1) outbreak experience among residents of a long term-care facility in Saudi Arabia during 2010 seasonal flu circulation. Infect Dis Rep. 2012;4:84-9.

23. Moattari A, Ashrafi H, Kadivar MR, et al. Antigenic variations of human influenza virus in Shiraz, Iran. Indian J Med Microbiol. 2010;28:114-9.

24. Tannous J, Zahreddine NK, Attieh RM, Mezher H, Kanafani Z, Kanj S. Influenza A outbreak in a hemodialysis unit at a tertiary care center in Lebanon. Antimicrobial Resistance Infect Control. 2019;2019:8.

25. Mohamed AG, BinSaeed AA, Al-Habib H, Al-Saif H. Communicability of $\mathrm{H} 1 \mathrm{~N} 1$ and seasonal influenza among household contacts of cases in large families. Influenza Other Respir Viruses. 2012;6:e25-9.

26. El Rhaffouli H, El Boukhrissi F, Bajjou T, et al. Seroprevalence of pandemic influenza A (H1N1)pdm09 in two regions in Morocco following the 2010-2011 influenza season. Pathol Biol (Paris). 2013;61:83-6.

27. Mese S, Uyanik A, Ozakay A, Ozturk S, Badur S. Influenza surveillance in Western Turkey in the era of quadrivalent vaccines: a 2003-2016 retrospective analysis. Hum Vaccines Immunother. 2018;2018: $1-29$.

28. Al-Awaidy S, Hamid S, Al-Obaidani I, et al. The burden of influenza-associated hospitalizations in Oman, January 2008-June 2013. PLoS ONE. 2015;10:e0144186.

29. Chlif S, Aissi W, Bettaieb J, et al. Modelling of seasonal influenza and estimation of the burden in Tunisia. East Mediterr Health J. 2016;22:460-7.
30. Reaves EJ, Mansour A, Mansour H, et al. Epidemiology of influenza among severe acute respiratory infections-damanhour, Egypt, 2009-2015. Am J Trop Med Hyg. 2016;95:393.

31. Rowlinson E, Dueger E, Mansour A, et al. Incidence and etiology of hospitalized acute respiratory infections in the Egyptian Delta. Influenza Other Respir Viruses. 2017;11:23-32.

32. Al Salman J, Alsharbati W, Hajeri M, Abdalla M, Hassan E, Alzaimoor K. Adult cases of H1N1 influenza admitted from 2015 to 2016. Bahrain Med Bull. 2018;40:145-9.

33. Makvandi M, Alvandi A, Aryan E, et al. Clinical and epidemiological characteristics of children with Influenza a h1n1 in Khuzestan, Iran during July 2009-April 2010. Jundishapur J Microbiol. 2013;2013:6.

34. Bouneb R, Mellouli M, Bensoltane H, et al. Characteristics and outcome of ill critical patients with influenza A infection. Pan Afr Med J. 2018;2018:29.

35. Ersoy AO, Unlu S, Oztas E, Ozler S, Uygur D, Yucel A. Influenza infections in the 2014-2015 season and pregnancy outcomes. J Infect Dev Ctries. 2017;11: 766-71.

36. Tinsa F, Barakizou H, Belhadj I, et al. Influenza A/ H1N1 pdm 09 in children's Hospital Bechir Hamza of Tunis. Tunis Med. 2018;96:348-52.

37. Ünver E, KarakeçiliA F, Çıkman A. Assessment of viral and atypical bacterial agents using polymerase chain reaction in patients presenting with signs of acute respiratory tract infection. West Indian Med J. 2018;67:298-303.

38. World Health Organization. Vaccines against influenza WHO position paper-November 2012. Releve Epidemiol Hebdomadaire. 2012;87:461-76.

39. World Health Organization. A manual for estimating disease burden associated with seasonal influenza. 2021. http://apps.who.int/iris/bitstream/ 10665/178801/1/9789241549301_eng.pdf?ua= $1 \& u a=1$. Accessed 02 Feb 2021.

40. Al Awaidi S, Abusrewil S, AbuHasan M, et al. Influenza vaccination situation in Middle-East and North Africa countries: report of the 7th MENA influenza stakeholders network (MENA-ISN). J Infect Public Health. 2018;11:845-50.

41. Newman LP, Bhat N, Fleming JA, Neuzil KM. Global influenza seasonality to inform country-level vaccine programs: an analysis of WHO FluNet influenza surveillance data between 2011 and 2016 . PLoS ONE. 2018;13:e0193263-e. 
42. Khan W, El Rifay AS, Malik M, Kayali G. Influenza research in the Eastern Mediterranean Region: a review. Oman Med J. 2017;32:359-64.

43. Moghoofei M, Monavari SH, Mostafaei S, et al. Prevalence of influenza A infection in the MiddleEast: a systematic review and meta-analysis. Clin Respir J. 2018;12:1787-801.

44. Caini S, Kusznierz G, Garate VV, et al. The epidemiological signature of influenza $B$ virus and its $\mathrm{B} /$ Victoria and B/Yamagata lineages in the 21st century. PLoS ONE. 2019;14:e0222381.

45. Tokars JI, Olsen SJ, Reed C. Seasonal incidence of symptomatic influenza in the United States. Clin Infect Dis. 2018;66:1511-8.

46. Baselga-Moreno V, Trushakova S, McNeil S, et al. Influenza epidemiology and influenza vaccine effectiveness during the 2016-2017 season in the Global Influenza Hospital Surveillance Network (GIHSN). BMC Public Health. 2019;19:487.

47. Puig-Barberà J, Burtseva E, Yu $\mathrm{H}$, et al. Influenza epidemiology and influenza vaccine effectiveness during the 2014-2015 season: annual report from the Global Influenza Hospital Surveillance Network. BMC Public Health. 2016;16(Suppl 1):757.

48. Glezen WP, Schmier JK, Kuehn CM, et al. The burden of influenza B: a structured literature review. Am J Public Health. 2013;103:e43-51.

49. World Health Organization. WHO EMRO|Influenza surveillance in the Region|News|Epidemic and pandemic diseases. Epidemic and pandemic-prone diseases. 2020. Accessed 02 Nov 2020.

50. Malik MR, Abubakar A, Kholy AE, et al. Improved capacity for influenza surveillance in the WHO Eastern Mediterranean Region: progress in a challenging setting. J Infect Public Health. 2020;13: 391-401.

51. World Health Organization. Summary report on the fifth meeting of the Eastern Mediterranean Acute Respiratory Infection Surveillance (EMARIS) network and second scientific conference on acute respiratory infections in the Eastern Mediterranean Region, Casablanca, Morocco. 2019. https://apps. who.int/iris/handle/10665/334164. Accessed 02 Nov 2020.

52. Zaraket H, Melhem N, Malik M, Khan WM, Dbaibo $\mathrm{G}$, Abubakar A. Review of seasonal influenza vaccination in the Eastern Mediterranean Region: policies, use and barriers. J Infect Public Health. 2019;12:472-8.

53. Ciblak MA, Ttenyurd MK, Asar S, TulunoĝLu M, Findiki N, Badur S. Influenza surveillance in nine consecutive seasons, 2003-2012: results from national influenza reference laboratory, Istanbul faculty of medicine, Turkey. Mikrobiyoloji Bulteni. 2012;46:575-93.

54. Almayahi ZK, Al Kindi H, Davies CT, et al. First report of human infection with avian influenza A(H9N2) virus in Oman: the need for a one health approach. Int J Infect Dis. 2020;91:169-73.

55. World Health Organization. Influenza update-379. 2020. https://www.who.int/influenza/surveillance_ monitoring/updates/latest_update_GIP surveillance/en/. Accessed 03 Nov 2020.

56. Rasooly MH, Sahak MN, Saeed KI, Krishnan SK, Khan W, Hassounah S. Capacity of the national influenza surveillance system in Afghanistan, a chronic conflict setting. East Mediterr Health J. 2016;22:475-81.

57. Farshad N, Saffar MJ, Khalilian AR, Saffar H. Respiratory viruses in hospitalized children with acute lower respiratory tract infections, Mazandaran Province, Iran. Indian Pediatr. 2008;45:590-2.

58. Soltani Z, Hosseini M, Shahidi M, Hedayati M, Kheiri MT. Molecular analysis of human influenza virus in Tehran, Iran. Intervirology. 2009;52:63-7.

59. Yavarian J, Mokhtari Azad T, Shafiei Jandaghi NZ, Nategh R. Amantadine-resistant influenza A (H3N2) viruses in Iran. Acta Virol. 2009;53:135-8.

60. Moattari A, Emami A, Moghadami M, Honarvar B. Influenza viral infections among the Iranian Hajj pilgrims returning to Shiraz, Fars province, Iran. Influenza Other Respir Viruses. 2012;6:e77-9.

61. Yavarian J, Naseri M, Shadab AA. Epidemiological aspects of pandemic influenza $\mathrm{A}(\mathrm{H} 1 \mathrm{~N} 1)$ virus from in Iran. Influenza Other Respir Viruses. 2012;6: $74-6$.

62. Afrasiabian S, Mohsenpour B, Bagheri $\mathrm{KH}$, et al. Epidemiological survey on pandemic influenza A (H1N1) virus infection in Kurdistan province, Islamic Republic of Iran, 2009. East Mediterr Health J. 2014;20:169-74.

63. Kenari SN, Haghshenas M, Mirzaei M, Rezaee MS, Tabrizi A. Prevalence of influenza A viruses in patients with flu symptoms attending Mazandaran provinces health centers, 2009-2013. J Mazandaran Univ Med Sci. 2014;24:1-10.

64. Pourakbari B, Mahmoudi S, Movahedi Z, et al. Viral etiology of acute lower respiratory tract infections in hospitalized young children in a children's referral hospital in Iran. Turk J Pediatr. 2014;56: 354-9. 
65. Haghshenas M, Jafarian E, Babamahmoodi F, et al. Prevalence of influenza A/H3N2 virus in northern Iran from 2011 to 2013. Caspian J Intern Med. 2015;6:116-9.

66. Khodadad N, Moattari A, Abadi MSS, et al. Prevalence of influenza $\mathrm{A}(\mathrm{H} 1 \mathrm{~N} 1) \mathrm{pdm} 09$ virus resistant to oseltamivir in Shiraz, Iran, during 2012-2013. Jundishapur J Microbiol. 2015;2015:8.

67. Faezi NA, Bialvaei AZ, Leylabadlo HE, Soleimani H, Yousefi M, Kafil HS. Viral infections in patients with acute respiratory infection in Northwest of Iran. Mol Genet Microbiol Virol. 2016;31:163-7.

68. Moasser E, Behzadian F, Moattari A, et al. Molecular characterization and phylogenetic analysis of human influenza A viruses isolated in Iran during the 2014-2015 season. Adv Virol. 2017;162: 1975-84.

69. Hosseini S, Karami M, Farhadian M, Mohammadi Y. Seasonal activity of influenza in Iran: application of influenza-like illness data from sentinel sites of healthcare centers during 2010-2015. J Epidemiol Glob Health. 2018;8:29-33.

70. Javanian M, Babazadeh A, Ebrahimpour S, Shokri M, Bayani M. Clinical and laboratory findings of patients with the possible diagnosis of influenza hospitalized in affiliated hospitals of Babol University of Medical Sciences, 2015-2016. Curr Issues Pharm Med Sci. 2018;31:113-6.

71. Yavarian J, Shafiei Jandaghi NZ, Naseri M, et al. Influenza virus but not MERS coronavirus circulation in Iran, 2013-2016: comparison between pilgrims and general population. Travel Med Infect Dis. 2018;21:51-5.

72. Haghshenas MR, Mousanejad P, Aarabi M, et al. Prevalence of influenza A/H1N1 virus in north of Iran, 2013 to 2017. J Mazandaran Univ Med Sci. 2019;29:148-56.

73. Hosssininasab A. Clinical signs and treatment outcomes of children with H1N1 influenza in two outbreaks, Southeastern Iran. Antimicrobial Resistance Infect Control. 2019;2019:8.

74. Mohebbi A, Fotouhi F, Jamali A, et al. Molecular epidemiology of the hemagglutinin gene of prevalent influenza virus $\mathrm{A} / \mathrm{H} 1 \mathrm{~N} 1 / \mathrm{pdm09}$ among patient in Iran. Virus Res. 2019;259:38-45.

75. Mood FS, Tabatabaei SM, Sharifi-Mood B, et al. The prevalence of respiratory viruses among patients with influenza-like illness in Zahedan, Southeastern Iran. Arch Clin Infect Dis. 2019;2019:14.

76. Rahmanian V, Shakeri M, Shakeri H, et al. Epidemiology of influenza in patients with acute lower respiratory tract infection in South of Iran (2015-2016). Acta Facultatis Medicae Naissensis. $2019 ; 36: 27-37$.

77. Sharify Mood F, Sharifimood B, Metanat M. Prevalence of respiratory viruses causing influenza-like illness in patients reffered to clinics and hospitals in Sistan-Baluchistan in the autumn and winter 2015-2016. Antimicrob Resist Infect Control. 2019;2019:8.

78. Nateghian A, Gouya MM, Nabavi M, et al. Demographic, clinical, and virological characteristics of patients with a laboratory-confirmed diagnosis of influenza during three consecutive seasons, 2015/2016-2017/18, in the Islamic Republic of Iran. J Clin Virol. 2020;124:104281.

79. Nasrallah GK, Meqdam MM, Al-Shurman A. Prevalence of parainfluenza and influenza viruses amongst children with upper respiratory tract infection. Saudi Med J. 2000;21:1024-9.

80. Altous M, Bsisu I, Obeidat Z, et al. Viral lower respiratory tract infections requiring hospitalisation among Jordanian adults. Respirology. 2019;24:189.

81. Zaraket H, Dbaibo G, Salam O, Saito R, Suzuki H. Influenza virus infections in Lebanese children in the 2007-2008 season. Jpn J Infect Dis. 2009;62: 137-8.

82. Zaraket H, Dapat C, Ghanem S, et al. Characterization of human influenza viruses in lebanon during 2010-2011 and 2011-2012 post-pandemic seasons. Intervirology. 2014;57:344-52.

83. Saito R, Akinobu H, Shaker RA, et al. Characterization of influenza outbreaks in Lebanon during the 2013/14 and 2014/15 seasons. East Mediterr Health J. 2016;22:547-51.

84. Saleh M, Bazzi L, Ismail E, et al. Influenza-associated severe acute respiratory infections in 2 sentinel sites in Lebanon-September 2015 to August 2016. Influenza Other Respir Viruses. 2018;12:331-5.

85. Allbrahim M, Assaf-Casals A, Massaad E, et al. Molecular epidemiology and genetic characterization of influenza B virus in Lebanon during 2016-2018. Infect Genet Evol. 2019;75:103969.

86. Al-Lawati J, Al-Tamtami N, Al-Qasmi A, Al-Jardani A, Al-Abri SA. Hospitalised patients with Influenza A (H1N1) in the Royal Hospital, Oman: experience of a tertiary care hospital, July-December 2009. Sultan Qaboos Univ Med J. 2010;10:326-34.

87. Al-Mahrezi A, Samir N, Al-Zakwani I, Al-Muharmi Z, Balkhair A, Al-Shafaee M. Clinical characteristics of influenza A H1N1 versus other influenza-like illnesses amongst outpatients attending a university 
health center in Oman. Int J Infect Dis. 2012;16: e504-7.

88. Kharosi ZA, Dildar B, Al-Maamari K, Al-Mubaihsi SM. Epidemiological and clinical characteristics of respiratory viral infections in adults at Sultan Qaboos University Hospital (SQUH), in Oman. Respirology. 2017;22:208-9.

89. Abdel-Hady DMA. Estimating the burden of influenza-associated hospitalization and deaths in Oman (2012-2015). Influenza Other Respir Viruses. 2018;12:146-52.

90. Badar N, Aamir UB, Mehmood MR, et al. Influenza virus surveillance in Pakistan during 2008-2011. PLoS ONE. 2013;2013:8.

91. Bashir U, Nisar N, Arshad Y, et al. Respiratory syncytial virus and influenza are the key viral pathogens in children \textless 2 years hospitalized with bronchiolitis and pneumonia in Islamabad Pakistan. Adv Virol. 2017;162:763-73.

92. Fatima A. NH1N1 influenza and risk of bacterial co infections among acutely ill children. Trans R Soc Trop Med Hyg. 2019;113:S262.

93. Bakri M, Samuh M, Azzeh M, et al. Molecular epidemiology survey and characterization of human influenza a viruses circulating among palestinians in East Jerusalem and the West Bank in 2015. PLoS ONE. 2019;2019:14.

94. Al-Romaihi HE, Smatti MK, Ganesan N, et al. Epidemiology of respiratory infections among adults in Qatar (2012-2017). PLoS ONE. 2019;14:e0218097.

95. Bakir TM, Halawani M, Ramia S. Viral aetiology and epidemiology of acute respiratory infections in hospitalized Saudi children. J Trop Pediatr. 1998;44: 100-3.

96. Al-Ayed MS, Asaad AM, Qureshi MA, Ameen MS. Viral etiology of respiratory infections in children in southwestern Saudi Arabia using multiplex reverse-transcriptase polymerase chain reaction. Saudi Med J. 2014;35:1348-53.

97. Ali G, Amer HM, Almajhdi FN. Hemagglutinin and neuraminidase genes of influenza B viruses circulating in Riyadh, Saudi Arabia during 2010-2011: evolution and sequence analysis. J Med Virol. 2014;86:1003-16.

98. Amer HM, Alshaman MS, Farrag MA, Hamad ME, Alsaadi MM, Almajhdi FN. Epidemiology of 11 respiratory RNA viruses in a cohort of hospitalized children in Riyadh. Saudi Arabia J Med Virol. 2016;88:1086-91.
99. Tolah AM, Azhar EI, Hashem AM, et al. Susceptibility of influenza viruses circulating in Western Saudi Arabia to neuraminidase inhibitors. Saudi Med J. 2016;37:461-5.

100. Al-Tawfiq JA, Ali AR, Hinedi KA. Influenza is more common than Middle East Respiratory Syndrome Coronavirus (MERS-CoV) among hospitalized adult Saudi patients. Travel Med Infect Dis. 2017;20: 56-60.

101. Altayep KM, Ahmed HG, Tallaa AT, Alzayed AS, Alshammari AJ, Ali-Talla AT. Epidemiology and clinical complication patterns of influenza A (H1N1 Virus) in Northern Saudi Arabia. Infect Dis Rep. 2017;9:6930.

102. Fagbo SF, Garbati MA, Hasan R, et al. Acute viral respiratory infections among children in MERS-endemic Riyadh, Saudi Arabia, 2012-2013. J Med Virol. 2017;89:195-201.

103. Assiri AM, Asiri SI, Banassir T, et al. Burden of influenza-related severe acute respiratory infections during Hajj season 1438 (2017). Lessons and future directions. Saudi Med J. 2017;2018(39):524-5.

104. Rabaan AA, Alshaikh SA, Bazzi AM, et al. Influenza A(H1N1)pdm09 epidemiology in the Eastern Province of Saudi Arabia. J Infect Public Health. 2018;11:636-9.

105. Al-Baadani A, Elzein F, Alhemyadi S, et al. Characteristics and outcome of viral pneumonia caused by influenza and Middle East respiratory syndromecoronavirus infections: a 4-year experience from a tertiary care center. Ann Thorac Med. 2019;14: 179-85.

106. Khan A, AlBalwi MA, AlAbdulkareem I, et al. Atypical influenza A(H1N1)pdm09 strains caused an influenza virus outbreak in Saudi Arabia during the 2009-2011 pandemic season. J Infect Public Health. 2019;12:557-67.

107. Kaygusuz S, Koksal I, Aydin K, Caylan R. Investigation of atypical bacteria and virus antigens in respiratory tract infections by use of an immunofluorescence method. Jpn J Infect Dis. 2004;57:33-6.

108. Yüksel H, Yilmaz O, Akcali S, et al. Common viral etiologies of community acquired lower respiratory tract infections in young children and their relationship with long term complications. Mikrobiyoloji Bulteni. 2008;42:429-35.

109. Carhan A, Altaş AB, Nurhan A, Uyar Y. Influenza surveillance results in 2007-2008 winter season in nine provinces of Turkey. Mikrobiyoloji Bulteni. 2009;43:235-41. 
110. Ceylan A, Dorman V, Yalim D, et al. Influenza surveillance in Diyarbakir between 2006-2009 years. TAF Prevent Med Bull. 2012;11:131-8.

111. Gülen F, Yıldız B, Çiçek C, Demir E, Tanaç R. Ten year retrospective evaluation of the seasonal distribution of agent viruses in childhood respiratory tract infections. Turk Pediatri Ars. 2014;49:42-6.

112. Karadag-Oncel E, Ciblak MA, Ozsurekci Y, Badur S, Ceyhan M. Viral etiology of influenza-like illnesses during the influenza season between December 2011 and April 2012. J Med Virol. 2014;86:865-71.

113. Çiçek C, Arslan A, Karakuş HS, et al. Prevalence and seasonal distribution of respiratory viruses in patients with acute respiratory tract infections, 2002-2014. Mikrobiyol Bul. 2015;49:188-200.

114. Cohen JM, Silva ML, Caini S, et al. Striking similarities in the presentation and duration of illness of influenza A and B in the community: a study based on sentinel surveillance networks in France and Turkey, 2010-2012. PLoS ONE. 2015;10:e0139431e.

115. Puig-Barberà J, Tormos $\mathrm{A}$, Trushakova $\mathrm{S}$, et al. The global influenza hospital surveillance network (GIHSN): a new platform to describe the epidemiology of severe influenza. Influenza Other Respir Viruses. 2015;9:277-86.

116. Altaş AB, Bayrakdar F, Korukluoğlu G. Influenza surveillance in five consecutive seasons during post pandemic period: results from national influenza center. Turkey Mikrobiyoloji Bulteni. 2016;50: 401-17.

117. Goktas S, Sirin MC, et al. Prevalence and seasonal distribution of respiratory viruses during the 2014-2015 season in Istanbul. Jundishapur J Microbiol. 2016;2016:9.

118. Gülcen BS, Feyzioğlu B, Özdemir M, Baykan M. Detection of influenza viruses from patients in university hospital. J Clin Virol. 2016;82:S115.

119. Meşe S, Asar S, Tulunoğlu M, et al. Evaluation of sentinel influenza surveillance of the last two seasons: 2013-2014 and 2014-2015. Mikrobiyol Bul. 2016;50:418-27.

120. Puig-Barbera J, Natividad-Sancho A, Trushakova S, et al. Epidemiology of hospital admissions with influenza during the 2013/2014 Northern Hemisphere Influenza season: results from the Global Influenza Hospital Surveillance Network. PLoS ONE. 2016;11:e0154970.

121. Özışık L, Durusu-Tanrı̈över M, Çıblak-Akçay M, et al. Mortality related factors in patients requiring hospitalization for influenza like illness. Mikrobiyol Bul. 2017;51:20-31.

122. Tanriover MDA. Poor outcomes among elderly patients hospitalized for influenza-like illness. Curr Med Res Opin. 2017;2017:1-7.

123. Aykac K, Karadag-Oncel E, Bayhan C, et al. Prevalence and seasonal distribution of viral etiology of respiratory tract infections in inpatients and outpatients of the pediatric population: 10 year followup. Turk J Pediatr. 2018;60:642-52..

124. Erçen Diken Ö, Arslan S, Akdoğan Ö, et al. Clinical, radiological and prognostic features of influenza cases in the influenza epidemic during years 2016-2017. Tuberk Toraks. 2018;66:144-9.

125. Ortac-Ersoy E, Er B, Eyupoglu S, et al. Outcome of influenza related intensive care unit admissions in 2017-2018 flu season: a multicenter study from Turkey. Intensive Care Med Exp. 2018;2018:6.

126. Aysert-Yildiz P, Aktas F. Investigation of influenza and respiratory viruses in hospitalised patients with influenza-like illness in an emergency room. J Infect Dev Ctries. 2019;13:1021-8.

127. Puig-Barberà J, Mira-Iglesias A, Burtseva E, et al. Influenza epidemiology and influenza vaccine effectiveness during the 2015-2016 season: results from the Global Influenza Hospital Surveillance Network. BMC Infect Dis. 2019;19:415.

128. Alsuwaidi AR, Al-Mekaini LA, Kamal SM, Narchi H, Souid A-K. Seroprevalence of influenza A and B viruses among unvaccinated children in the United Arab Emirates: a cross-sectional study. BMC Res Notes. 2017;10:379.

129. Jeon JH, Han M, Chang HE, et al. Incidence and seasonality of respiratory viruses causing acute respiratory infections in the Northern United Arab Emirates. J Med Virol. 2019;91:1378-84.

130. Al Amad M, Al Mahqri A, Al SA. Severe acute respiratory infections associated with influenza and non-influenza viruses-Yemen, 2011-2014. Int J Infect Dis. 2016;45:291.

131. Thabet AAK, Al-Kohani A, Shadoul A, Al-Mahaqri AA. Characteristics of severe acute respiratory infection associated hospitalization in Yemen, 2014/15. Eastern Mediterr Health. 2016;22:440-4.

132. Al Amad MA, Al Mahaqri AA, Al Serouri AA, Khader YS. Severe acute respiratory infections with influenza and noninfluenza respiratory viruses: Yemen, 2011-2016. Inquiry. 2019;56:46958019850731. 
133. Radin JM, Katz MA, Tempia S, et al. Influenza surveillance in 15 countries in Africa, 2006-2010. J Infect Dis. 2012;206(Suppl 1):S14-21.

134. Ait-Aissa A, Derrar F, Hannoun D, Gradi EA, Scaravelli D, Bouslama $Z$. Surveillance for antiviral resistance among influenza viruses circulating in Algeria during five consecutive influenza seasons (2009-2014). J Med Virol. 2018;90:844-53.

135. Derrar F, Voirin N, Khanafer $\mathrm{N}$, et al. Influenza surveillance during the 2009-2010, 2010-2011, 2011-2012, and 2012-2013 seasons in Algeria. J Med Virol. 2019;91:1394-9.

136. Shafik CF, Mohareb EW, Yassin AS, Amin MA. Viral etiologies of lower respiratory tract infections among Egyptian children under five years of age. BMC Infect Dis. 2012;12:350.

137. Refaey S, Amin M, Labib M, Kandeel A. Influenza virus positivity and circulating subtypes among cases of influenza-like illness and severe acute respiratory infection, Egypt, 2012-2015. East Mediterr Health J. 2016;22:527-36.

138. Elhakim MA, Rasooly MH, Fahim M, et al. Epidemiology of severe cases of influenza and other acute respiratory infections in the Eastern Mediterranean Region, July 2016 to June 2018. J Infect Public Health. 2020;13:423-9.
139. Barakat A, Ihazmad H, Benkaroum S, Cherkaoui I, Benmamoun A, Youbi MA. Influenza surveillance among outpatients and inpatients in Morocco, 1996-2009. PLoS ONE. 2011;2011:6.

140. Anga LAF, Idrissi A, Hassar M, Cadi R, Nourlil J. Molecular detection and identification of influenza viruses in Casablanca during 2010-2011. Clin Chem Lab Med. 2012;50:A117-8.

141. Elfalki F, Ihazmad H, Bimouhen A, et al. Detection of influenza $B$ viruses with reduced sensitivity to neuraminidase inhibitor in Morocco during 2014/15 season. East Mediterr Health J. 2016;22: 453-9.

142. El-Moussi A, Ben-Hadj-Kacem MA, Ledesma J, et al. Genetic diversity of influenza B virus in 2009-2010 and 2010-2011 in Tunisia. Med Mal Infect. 2013;43: 337-44.

143. Meddeb K, Boujelbn MA, Rouis S, et al. Severe acute respiratory infection (SARI): Frequency and microbiology in a Tunisian medical ICU. Intensive Care Med Exp. 2018;2018:6.

144. Al-Awaidy S, Hamid SA. The burden of influenzaassociated hospitalizations in Oman, January 2008-June 2013. PLoS ONE. 2015;10:e0144186. 